\title{
Protection of Distributed Generation: Challenges and Solutions
}

\author{
Umair Shahzad, Salman Kahrobaee, Sohrab Asgarpoor \\ Department of Electrical and Computer Engineering, University of Nebraska-Lincoln, Lincoln, Nebraska, USA \\ Email: umairshahzada@hotmail.com,skahrobaee@huskers.unl.edu, sasgarpoor1@unl.edu
}

How to cite this paper: Shahzad, U., Kahrobaee, S. and Asgarpoor, S. (2017) Protection of Distributed Generation: Challenges and Solutions. Energy and Power Engineering, 9, 614-653. https://doi.org/10.4236/epe.2017.910042

Received: August 31, 2017

Accepted: September 18, 2017

Published: September 21, 2017

Copyright $\odot 2017$ by authors and Scientific Research Publishing Inc. This work is licensed under the Creative Commons Attribution International License (CC BY 4.0).

http://creativecommons.org/licenses/by/4.0/

(c) (i) Open Access

\begin{abstract}
Distributed generation (DG) is the future of energy. This technology allows the bidirectional flow of power within an electrical network. Researchers are faced with many challenges to the accurate implementation of protection schemes for DG-connected distribution network. The schemes designed must satisfy the performance requirements of selectivity, reliability, and sensitivity. Most researchers opine that conventional protection schemes based on over current detection are insufficient to completely and accurately protect a DG-connected distributed power system. There are many challenges that need to be tackled before embarking upon the journey to successfully implement these schemes. This paper summarizes the major challenges which one can encounter while designing protection schemes for DG-connected distribution networks. Some possible solutions from the literature are also mentioned. Moreover, a suggested solution for protecting future active distribution networks is provided. It is expected that this paper will act as a benchmark for future researchers in this field to tackle the challenges related to the protection of active distribution networks.
\end{abstract}

\section{Keywords}

Distributed Generation (DG), Energy, Selectivity, Sensitivity, Reliability, Protection Schemes, Active Distribution Networks

\section{Introduction}

Distributed generation (DG) technology is gaining in popularity due to the everincreasing demand for energy, the depletion of fossil fuel resources and a greater emphasis on clean energy. The power network has been intrinsically radial. Introduction of DG makes it bidirectional as energy can flow from DG as well as the main utility grid. This causes numerous complications in regard to the system 
voltage profile, power quality, adequacy, security, power flow control, energy management, frequency control and protection. System protection, in the presence of DG, has been a conspicuous issue in recent years and needs immediate consideration [1] [2] [3].

This paper aims to present challenges and issues related to protection of active distribution networks, and review state-of-the-art solutions, proposed so far, for these problems. It also gives a critical analysis of each method presented. Protection of DG-connected distribution networks is a serious issue which has caught the attention of researchers lately. Therefore, it is imperative to analyze various challenges and present suitable solutions associated with protection of these networks. This paper is organized in a manner such that Section 1 briefly reviews literature on protection of DG-connected distribution networks. Sections 2-3 briefly introduce DG, its applications; microgrids and their major issues. Sections 4-5 talk about fault types and sources. Sections 6-7 discuss major challenges and possible solutions, regarding protection of DG, including microgrids, which have been presented in the literature. Section 8 concludes the paper and proposes a novel solution for tackling protection of active distribution networks.

\section{Literature Review}

Over the past few decades, the use of renewable energy resources has augmented due to progression in exploiting renewable resources, worsening of problems in transmission and distribution lines, a rising propensity to generate power at distribution level, reduction in fossil fuels, and the necessity for enhanced power quality and reliability [4] [5]. These sources of power generation are called DG sources. Installing DG resources in an electric power system changes its behavior while enabling utilities to take advantages of smaller and more flexible resources. This novel technology has altered power systems into smaller networks known as microgrids. Microgrid is an active distribution network consisting of DG resources, different loads at the voltage level of distribution, and energy storage elements. From a network standpoint, a microgrid is beneficial because it is a controlled unit and can be used as a concentrated load. From the perspective of customers, a microgrid can be designed to meet their special requirements such as enhanced local reliability, less feeder losses, better local voltages, amplified efficiency, voltage sag correction, and supply of uninterruptible power. From an environmental viewpoint, a microgrid reduces environmental pollution and global warming because it generates less carbon monoxide [6] [7]. Although, a microgrid is a suitable replacement for limited fossil fuels and can efficiently solve power generation difficulties, it is still mostly limited to a laboratory scale due to many technical challenges. Some of the most important of these challenges are protection, security, power quality, operation in normal and islanded modes, voltage and frequency control, plug-and-play operation, energy management, and system stability [8]. 
Designing an appropriate method for microgrid protection is difficult in two significant ways. One is that microgrids are mainly dynamic networks. In fact, a load or a DG unit can be connected to or disconnected from a microgrid at any given time. Another challenge is that microgrids can operate in both grid-connected and islanded modes with different short-circuit currents [9]. Therefore, a comprehensive design scheme must protect the network in both modes [10]. It is vital for a properly operating microgrid that the interconnecting switch (the switch connecting microgrid with the main grid) must open during any unacceptable power quality disturbance or fault on the main grid and the DGs must be capable to carry the load on the islanded section while maintaining the acceptable levels of voltage and frequency for the islanded loads. Suitable load-shedding schemes should be implemented if DG generation capacity does not fulfill the load demand of islanded system. Depending on the technology of switch, some momentary power disruptions may happen (DGs may seize to energize the islanded section for some short period of time) during transition from grid-connected to islanded mode; in this situation, the DGs in the islanded portion must be capable of quick restart and picking up the islanded load after opening of the switch. The DGs must supply the real and reactive power requirements in the islanded mode and should sense a fault current downstream of the interconnecting switch. After the restoration of the main grid supply, the switch should not close until both the grid and the islanded system are properly synchronized i.e. voltage, frequency, and phase angle of both the systems must be within acceptable limits. For faults occurring within the islanded system, there must be protection system which can detect the fault and speedily isolate the faulty portion from the rest of the system ensuring minimum loss of generation and load interruptions. Moreover, the protection system of islanded system must be more sensitive because fault currents in islanded system will be of much lower magnitudes than those of the grid-connected system [11].

Numerous technical issues of the protection system, with emphasis on protection coordination problem, are discussed in [12]. Novel protection schemes for multiphase and phase-to-ground faults in medium voltage (MV) microgrid are suggested in [13]. In [14], a coordinated method to manage both network protection and DG interface protection is proposed. Authors in [15] have devised a protection scheme using digital relays with communication network for the microgrid. To provide an effective network protection to a meshed microgrid, a multilevel approach is implemented in [16]. The application of admittance relay for protection of the converters used for DG sources is elaborated in [17].

\section{Distributed Generation}

IEEE defines DG as "generation of electricity by the facilities that are sufficiently smaller than central generating plants to allow interconnection at nearly any point in a power system". Electric Power Research Institute (EPRI) defines DG as "Smaller power sources that can be aggregated to provide power necessary to 
meet regular demand." However, there are some discrepancies in these definitions as they do not mention anything about the power rating, technology employed, mode of operation and environmental impact of the DG source. Reference [18] classifies DG sources based upon their power ratings: micro, small, medium, and large, as shown in Table 1. DG has also been classified, according to coupling type in [19], as shown in Figure 1.

\subsection{Applications of Distributed Generation}

There are many reasons which have persuaded the researchers and energy experts to shift the paradigm towards DG. Some major application factors, due to which the scope of DG is improving and is gaining popularity, are discussed below [18].

\subsubsection{Liberalization of Electricity Markets}

It has been observed that there is an augmented interest in DG recently by electricity suppliers. The primary reason is that they see it to maintain a good repute in the market where consumers look for the appropriate electricity service. DG permits stakeholders of the electricity sector to adapt to varying market conditions in a much flexible manner. In liberalized markets, it is imperative to adhere

Table 1. DG classification based on power rating.

\begin{tabular}{cc}
\hline DG Type & Power Rating \\
\hline Micro & $<5 \mathrm{~kW}$ \\
Small & $5 \mathrm{~kW}-5 \mathrm{MW}$ \\
Medium & $5 \mathrm{MW}-50 \mathrm{MW}$ \\
Large & $>50 \mathrm{MW}$ \\
\hline
\end{tabular}

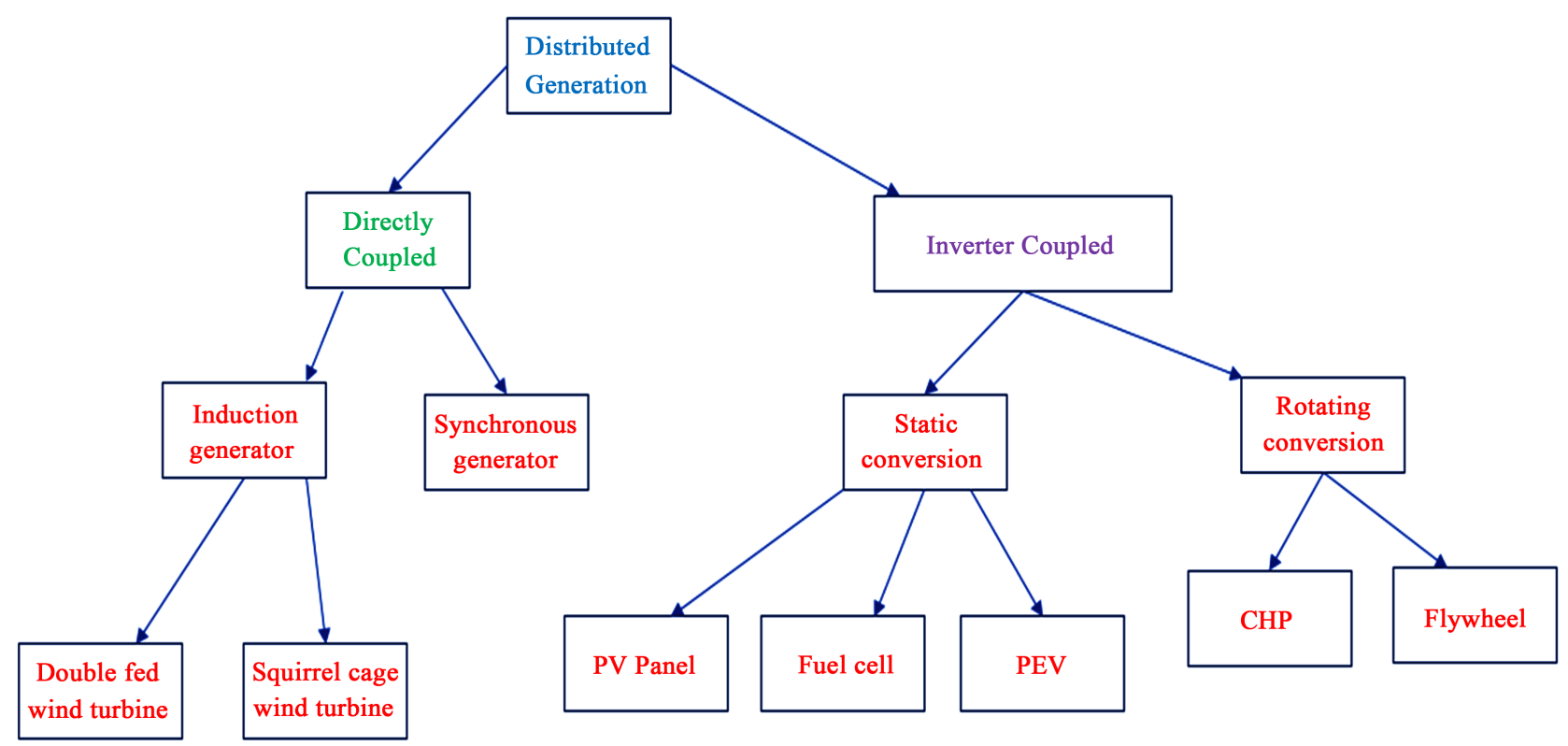

Figure 1. DG classification based on coupling. 
to the varying financial situation. In many situations, DG technologies provide flexibility owing to their smaller sizes and shorter construction times compared to other kinds of conventional large central power stations. Nevertheless, this time reduction is not that obvious. For example, a specific area might show more resistance to wind power and solar energy due to various reasons.

\subsubsection{Peak Shaving}

Many DG technologies are flexible in numerous aspects. These aspects majorly include size, operating mode, and extent of expandability. Utilizing DG allows to respond amenably to variations in electricity price developments. DG then serves as a border against these price instabilities. Seemingly, this is the primary driver for the demand for DG in various countries i.e. using DG for continuous or peaking purpose. Occasionally, the energy efficiency is controversial. For instance, presently, in Europe, market demand for DG is controlled by heating applications (mainly through CHP), introduction of renewable energy technologies and potential efficiency improvements.

\subsubsection{Reliability and Power Quality}

Another major motivating factor for using DG is supply quality and reliability. Reliability issues indicate sustained interruptions i.e. voltage drops near to zero. The liberalization of electricity markets makes consumers extra conscious of the importance of reliability of electricity supply. It must be mentioned that customers do not bother about supply interruptions as they do not feel it as a great peril. Nevertheless, this may vary in liberalized markets. A high reliability level means a high investment and maintenance costs for the network and generation organization. Due to the enticements for saving money that come from introducing healthy rivalry in generation and actions from regulators the goal of which is to attain short-term tariff discounts for network companies, it might be that levels of reliability decline. Yet, having a reliable power supply is significant for society in general, and industry in specific (chemicals, petroleum, refining, paper etc.). Companies may find the reliability of the grid at a dangerously low level and agree to invest in DG units to upsurge total reliability of supply to the wanted level. Besides, voltage drops to near zero (reliability problems), one can also have smaller deviations of voltage. The latter deviations are considered features of power quality. Power quality refers to the extent to which power characteristics align with the ideal waveforms of sinusoidal voltage and current. Therefore, firmly speaking, power quality incorporates reliability. DG technologies can also contribute in providing benefits in the form of greater reliable power for industries which necessitate uninterrupted service. EPRI reported that power outages and quality disturbances cost American businesses approximately $\$ 119$ billion annually. In 2001, International Energy Agency (IEA) estimated that the average cost of a one-hour power outage was $\$ 6,480,000$ for brokerage operations and $\$ 2,580,000$ for credit card operations. These figures increase remarkably for the semiconductor industry, where a two-hour power outage can 
cost nearly $\$ 48,000,000$. Given these large figures, it remains no secret why numerous industries have already installed DG units to ensure reliable power supplies.

\subsubsection{Use of Local Network}

DG could partially serve as an auxiliary network for investments in transmission and distribution capacity (demand for DG from Transmission and Distribution companies) or as a bypass for transmission and distribution costs (DG demand from electricity consumers). This is only probable to the degree that substitute primary fuels are locally accessible in adequate numbers. For instance, augmented employment of DG could lead to new overcrowding problems in other networks, such as the oil distribution network.

\subsubsection{Grid Support}

DG can also contribute in the delivery of subsidiary services, including those essential to maintain a steady grid operation of the customers. This can include the ability to generate active power when demanded by grid network operator, for example, to keep a system in steady state when its frequency is declining due to an abrupt drop in generation or due to a severe fault on the main grid.

\subsubsection{Ancillary Benefits}

Environmentalists and researchers commonly opine that DG technologies can provide ancillary benefits to society. Large centralized power plants emit substantial amounts of harmful gases like carbon monoxide, sulphur oxides, and nitrogen oxides. The Environmental Protection Agency (EPA) has long noted the correlation between high levels of sulphur oxide emissions and the formation of acid rain. As they concentrate the amount of power they produce, large power plants also focus their pollution and waste heat, often destroying aquatic habitats and marine biodiversity. On the contrary, recent studies have established that prevalent use of DG technologies substantially reduces emissions: a British analysis projected that domestic CHP technologies reduced carbon dioxide emissions by $41 \%$ in 1999; a similar report on the Danish power system observed that extensive use of DG technologies have cut emissions by about 30\% from 1998 to 2001. Furthermore, as DG technologies remain autonomous of the grid, they can deliver emergency power for many public services such as hospitals, universities, and airports. Last, but not the least, DG can assist a country upsurge its variety of energy sources. Some of the DG technologies such as wind turbines, solar photovoltaic panels, and hydroelectric turbines, do not use any kind of fossil fuels while others such as fuel cells, microturbines, and some internal combustion units burn oil and natural gas. The increasing assortment can protect the economy from price shocks, interruptions, and fuel shortages.

\subsubsection{Upgradability}

DGs have the ability of upgradability. Suppose a large wind farm, consisting of various turbines, has a life time of 40 years. It is expected that efficiency of turbines 
will improve over few years but it is very expensive and impractical to replace the whole farm at once. It is problematic to replace only a few turbines as their replacement will affect other turbines too. On the contrary, smaller wind farms in more locations can much easily incorporate installation of new turbines, thereby gradually increasing the production. Similar phenomenon is applicable to other kinds of DG sources.

\subsubsection{Enhancement of Energy Security}

DGs deliver more energy security as compared to large conventional power plants in case of harsh weather conditions, natural catastrophes, human mistakes, and cyber-attacks. If a centralized power plant collapses, an enormous blackout may occur in the adjacent residential area and it can lead to a calamity for the people nearby. For instance, after the infamous earthquake, known as Tsunami, and the failure of cooling systems at Fukushima-I Nuclear Power Plant and issues concerning other nuclear facilities in Japan on March 11, 2011, a vast blackout occurred for a long duration of time. A nuclear emergency was declared in Japan and 140,000 residents, within 12 miles radius of the plant, were vacated.

\subsection{Trends of DG in U.S. Market}

As the use of advanced energy technologies is increasing, the desire of customers in the United States (U.S.), for greater control of their energy, is increasing. Over the past few years, some major grid incidences and long-term outages have brought reliability and resiliency of the grid into the picture. The use of fossil fuels (coal, oil, gas) is becoming expensive. Moreover, they are being depleted at a rapid rate. Renewable energy generation deployment is constantly increasing which is forcing the utilities and customers to shift the energy trends. These renewable sources require massive control and operation functions which can be satisfied by bringing only the DG sources into the big picture. DG can be utilized to avoid congestion and laying out new transmission lines to fulfill consumer power demand. Recently, a lot of energy companies in the U.S. are responding to this change. On June 23, 2008, the Public Service Commission (PSC) established the New York Energy Efficiency Portfolio Standard proceeding. As part of a statewide program to reduce New Yorkers' electricity usage 15 percent of forecast levels by the year 2015, with comparable results in natural gas conservation, the Commission established interim targets and funding through the year 2011. New York's utilities were made to file energy efficiency programs, and the New York State Energy Research and Development Authority (NYSERDA) was invited to submit energy efficiency program proposals for Commission approval. Since June 2009, the Commission has approved over 90 electric and gas energy efficiency programs, along with rules to lead implementation and measure results. In the 2012 through 2015 incentive period, the New York PSC established incentive pools, totaling \$36 million for electric utilities and \$14 million for gas utilities. On June 23, 2011, New York passed historic on-bill financing legislation 
to intensely expand the state's new energy efficiency program, popularly known as Green Jobs/Green NY. The new law will finally enable moderate-income property owners to access safe loans for retrofits, and use energy savings to repay the loan using their utility bills. In 1999, the Public Utility Commission of Texas adopted rules for the state's Renewable Energy Mandate, establishing a renewable portfolio standard, a renewable-energy credit trading program, and renewable-energy purchase requirements for competitive retailers in Texas. The 1999 standard called for 2000 megawatts of new renewables to be installed in Texas by 2009 , in addition to the 880 megawatts of existing renewables generation at the time. For instance, PV-type DG has achieved unprecedented levels of penetration in the U.S. from under $2 \mathrm{GW}$ in 2009 to over $8 \mathrm{GW}$ by 2014. A combination of federal tax policies, state mandates and incentives, business model and financial innovation have combined to enable the DG market successes. Challenges aside, the U.S. has seen consistent growth in its DG markets, with anticipated gigawatt-scale deployments year-over-year. The variety of policies and plans that have, in combination, encouraged this growth, comprise a body of lessons learned and unsurpassed practices, that can be selectively applied in other countries to stimulate their own DG markets

System operators in the U.S., already coping with non-dispatchable utility-scale renewable electricity, now must grapple with non-dispatchable distributed generation. This puts flexibility at a premium for those DG sources that are dispatchable to such an extent that the system operators in some states, including Texas and California, have been developing incentives to reward flexible operation. If these prove to be a success, other states are expected to follow the same trend. Some policy-makers are simplifying the development of markets around distributed generation, such as New York state with its "Reforming the Energy Vision" (REV) strategy [20].

\section{Microgrid}

According to the U.S. Department of Energy (DOE), a microgrid is "a group of interconnected loads and distributed energy resources within clearly defined electrical boundaries that acts as a single controllable entity with respect to the grid (and can) connect and disconnect from the grid to enable it to operate in both grid-connected or island-mode.” [3] [21]

\subsection{Modes of Operation}

A typical microgrid operates in two modes which are defined below [3] [21].

\subsubsection{Grid-Connected Mode}

Under this mode, the main utility grid is active and the static switch is closed. All feeders are getting their power from the main grid. In other words, critical loads (on Feeders A and B) and noncritical loads (on Feeder C) are being supplied by the main grid. Figure 2 portrays this situation. PCC refers to the point of common coupling [3] [21]. 


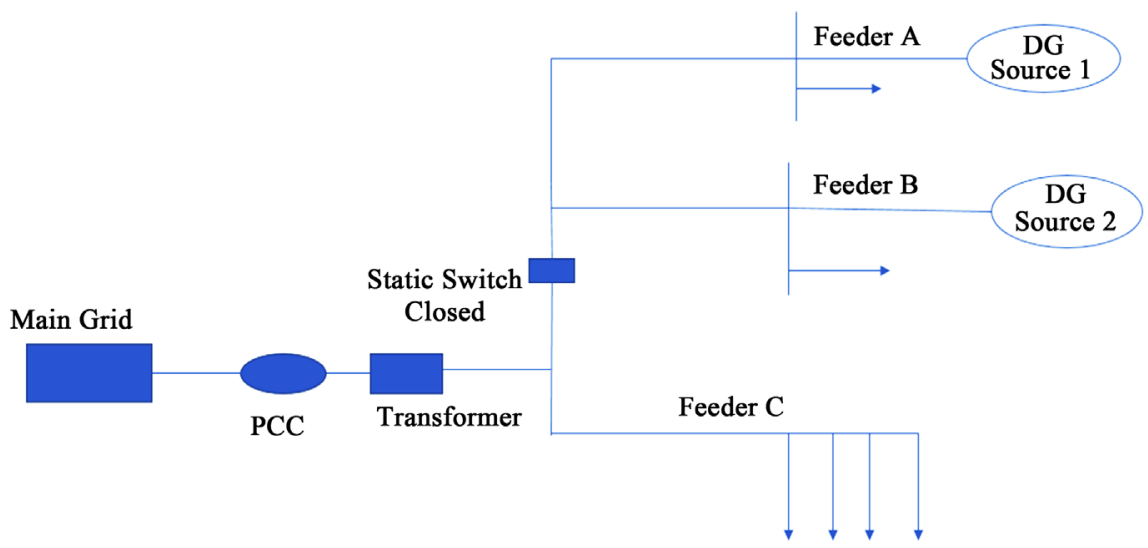

Figure 2. Microgrid: grid-connected mode.

\subsubsection{Islanded Mode}

Under this mode, the main grid is cut off and is not supplying power. The main grid might be turned off due to fault or maintenance purposes. The static switch is open. Microsources supply Feeders A and B. Feeder C is dead as it is not sensitive. In other words, critical loads are being supplied power by the micro sources; and non-critical loads (on Feeder C) are cut-off from the system. Figure 3 displays this situation [3] [21].

\subsection{Core Issues of Microgrid}

This section presents some core issues that can be encountered in a typical microgrid [22].

\subsubsection{Voltage and Frequency Control}

In a typical electric power system, active and reactive power generated must be in balanced condition with the power consumed by the loads, including the losses in the transmission/distribution lines. The unbalanced condition occurs when power generated is not equal to the power demanded. This causes a deviation of the system frequency from its set point value $(60 \mathrm{~Hz})$. The aim of voltage and frequency control is to ensure that both the voltage and the frequency remain within predefined limits around the set point values by regulating active and reactive power generated or consumed. In a typical microgrid, a daunting task is to operate more than one DG source on the island. In such case, it is not possible to use the active and reactive power control. It is essential to regulate the voltage during microgrid operation by using a voltage versus reactive power droop controller for attaining local reliability and stability. Each DG source is equipped with the power frequency droop characteristic during islanded operation. A dynamic analysis of generation control scheme, consisting of active power-frequency and reactive power-voltage controllers, for the inverter based DG sources, is discussed in [23]. These droop-based controllers allow decentralized operation of the microgrid without communication between the DG sources. Small-signal models were established for investigation on dynamic behavior for a chain microgrid comprising of " $n$ " DG sources. The small-signal 


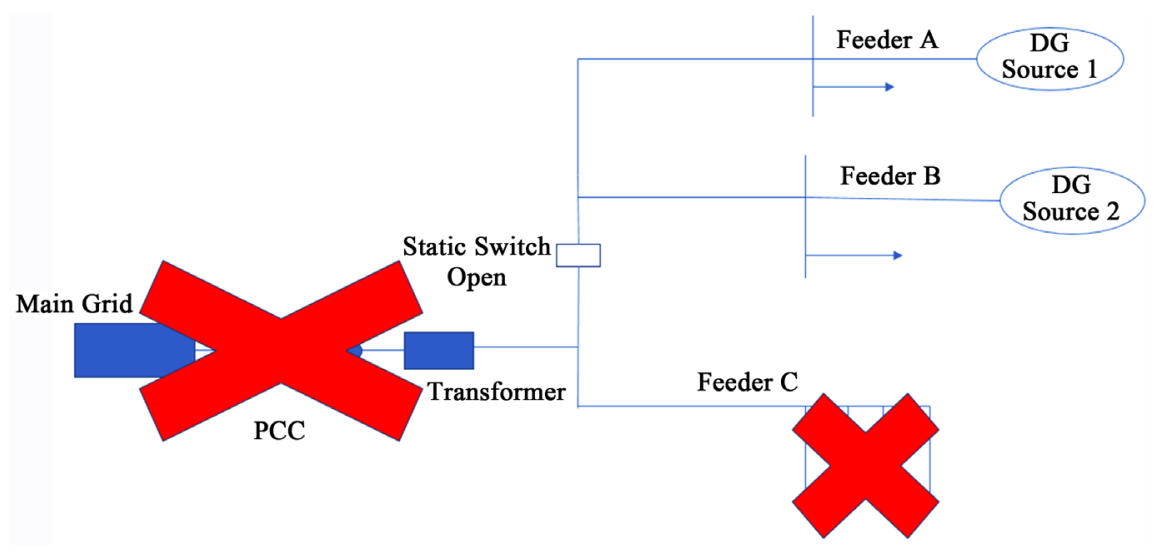

Figure 3. Microgrid: Islanded mode.

state-space model of autonomous operation of inverter-based microgrid is presented [24]. Each DG inverter has an outer power loop based on droop control to share the real and reactive powers with other DG sources. Voltage and current controllers are used in inverter internal controls to reject high frequency disturbances and damp the output filter to prevent any resonance with external network.

\subsubsection{Islanding}

Islanding is a small-scale representation of the future interconnected grid with many DG sources. The microgrid provides a yardstick between island and the interconnected grid. It can be used in the large interconnected grid with the high penetration of DG sources. The islanding control strategies are imperative for the operation of a microgrid in the autonomous mode. Two kinds of control strategies of islanding are utilized to operate an inverter. The PQ inverter control is used to supply a given active and reactive power set point and the voltage source inverter (VSI) control is controlled to feed the load with predefined values for voltage and frequency. The VSI real and active power output is defined according to load conditions. It acts as a voltage source with the magnitude and frequency of the output voltage controlled through droop. An islanding detection algorithm was established in [25] for switching between the interface controls. The islanding detection algorithm is efficient and can detect islanding even under situations when load and DG capacity are nearly the same. The proposed control scheme can maintain both voltage and frequency within the standard permissible levels during islanded operation of the DG. Such control strategy could be used to supply critical loads in the distribution system during utility outage.

\subsubsection{Power Imbalance}

A power imbalance happens during the transition process from grid-connected to islanded mode when the microgrid is absorbing or supplying power to the main grid before disconnection. Energy storage units are used to maintain power balance due to the slow dynamic response and low inertia of some DG 
sources. When a microgrid goes back from islanded mode to grid-connected mode, it is synchronized by ensuring that the magnitude and phase of the voltages, across the synchronizing device, are equal. A high-speed static switch, with suitable sensing capability, may be used for disconnection.

\subsubsection{Harmonics}

The harmonic currents, which can occur in a typical microgrid, need to be abridged to reduce harmonic losses. For this to take place successfully, harmonic compensation methods have been proposed in [26]. The harmonics happens due to operation of power electronic converters. The harmonic voltage and current should be restricted to the acceptable level at the point of DG connection to the network. To ensure that harmonic voltage is within acceptable values, each source of harmonic current can allow only a limited contribution, as per the IEC-61400-36 guideline. The abrupt switching causes huge reduction in lower order harmonic currents compared to the line-commutated converter, but the output current has increased frequency content which can easily be filtered-out using RL filters.

\subsubsection{Changes in Topology}

Microgrids operate in two different modes: grid-connected and islanded (stand-alone). Topological changes occur in low voltage (LV) networks due to connection/disconnection of generators and loads. Also, there is intermittence in the generation of numerous renewable resources (solar, wind etc.) connected in the microgrid. Collection of information and communication technologies to the power grid technologies is altering the architecture and operation of the conventional grid. Microgrid topology can be installed in areas, such as city buildings, factories, homes, or even, rural farms. For different situations, depending on consumer requirements, strength of the utility grid, and the number of available DG sources, AC, DC or hybrid microgrid can be implemented. To augment the dependability of the microgrid, an energy storage system can be established to support the bus voltage when the microgrid goes from the grid-connected mode to islanded mode. This energy storage system can be charged from the main bus voltage with the aid of a converter.

\subsubsection{Economic Aspects}

With an active management control approach and ability to operate in autonomous mode, a bunch of microgenerators, electricity storage and electrical loads can be operated, within the microgrids framework, to provide higher supply reliability to customers. Solutions are required, not only to make these concepts technologically practicable and safe to operate, but also to be commercially feasible, economically efficient and reinforced by electricity regulations. Thorough analysis of investigations on various economic, regulatory, and commercial issues, faced by the development of microgrids in various projects, is need of the hour. The potential economic advantages and contributions to the environment, resulting from applications of microgrid technologies, should be 
considered.

\subsubsection{Protection}

The transition towards microgrid leads to new necessities and challenges for protection that needs to be adaptive for variations in the network topology along with connection of active resources. The protection challenges, associated with microgrids, evolve from adding DG sources to the grid. The effects of adding DG resources to networks are plentiful, including changing power flow and increased or decreased short circuit levels among other harmful effects. The effects of DG on the protection also rely on the kind of DG source used. Synchronous generator can sustain higher fault current for longer periods of time while the fault current generated by an induction generator decays very rapidly. Converter-interfaced DG sources have short-circuit current generating capabilities limited to approximately 2 - 3 times their rated current. This creates issues for protection, as the current may not be large enough, to be detected with traditional overcurrent protection. Self-healing is a feature which is strongly coupled to protection and automation. With this feature, it is possible to continue to supply part of the network, after fault, by taking backup supply into use or by operating part of the network as a microgrid. The protection and automation system must have the ability to operate to deliver power to areas not affected by fault.

\subsubsection{Interconnection of DG: A Controversial Issue}

Interconnection is the process of connecting a DG source to the electric grid. Before connecting, the DG system owner must obtain written approval from the local utility in the form of an interconnection service agreement and subsequent authorization to connect. Different power companies enforce various requirements to connect a DG to the utility grid. There is a disagreement on various clauses, for instance, some companies require customer to be responsible for all protection and control aspects of DG, while others keep the authority of these critical functions to themselves. For example, the state of Nebraska requires the customer to have net metering and supply an external disconnect switch, which can automatically isolate from the main grid, in the event of a fault or disturbance. On the other hand, the state of Ohio does not address the issue of disconnect switch. Therefore, there is a need to have a consistent set of rules, which can be followed, for proper connection of DG sources to the main grid, without any uncertainty.

\section{Fault Types}

Generally, two kinds of faults are considered in the literature: three-phase symmetrical faults and single line-to-ground faults. The reason being that single line-to-ground is the most common fault and three-phase fault is typically the most severe. Most papers have covered shunt faults (single line-to-ground, line-line, double line-ground, three-phase faults). Very few papers have given 
attention to series faults (open conductor faults or high impedance faults). The reason is that they are not very hazardous as compared to shunt faults. Moreover, it has been practically observed that in most cases, series faults eventually change into shunt faults [27]. Table 2 shows statistics of occurrence for shunt faults.

Further, the probability of faults on different elements of the power system is disparate. The transmission and distributions lines which are exposed to open atmosphere are the most likely to be subjected to faults. Indoor equipment (underground cables and power generators) is least likely to be subjected to faults. The fault statistics regarding power system elements are shown in Table 3 [27].

\section{Sources of Faults}

There are many sources of faults, including natural events, physical accidents, equipment failure and misoperation [28]. They are summarized in Figure 4. As evident from the figure, natural events such as lightning, earthquakes, sandstorms, snowstorms etc. have a good share in causing system faults. Sometimes, human error and physical accidents play a negative role by inducing faults on lines and transformers.

Table 2. Fault statistics based on fault type.

\begin{tabular}{|c|c|c|}
\hline Fault Type & Occurrence Probability (\%) & Severity \\
\hline Single Line to Ground (SLG) & 85 & Least \\
\hline Line-Line (LL) & 8 & \\
\hline Double Line to Ground (LLG) & 5 & \\
\hline Three Phase Bolted (LLL) & 2 & Most \\
\hline
\end{tabular}

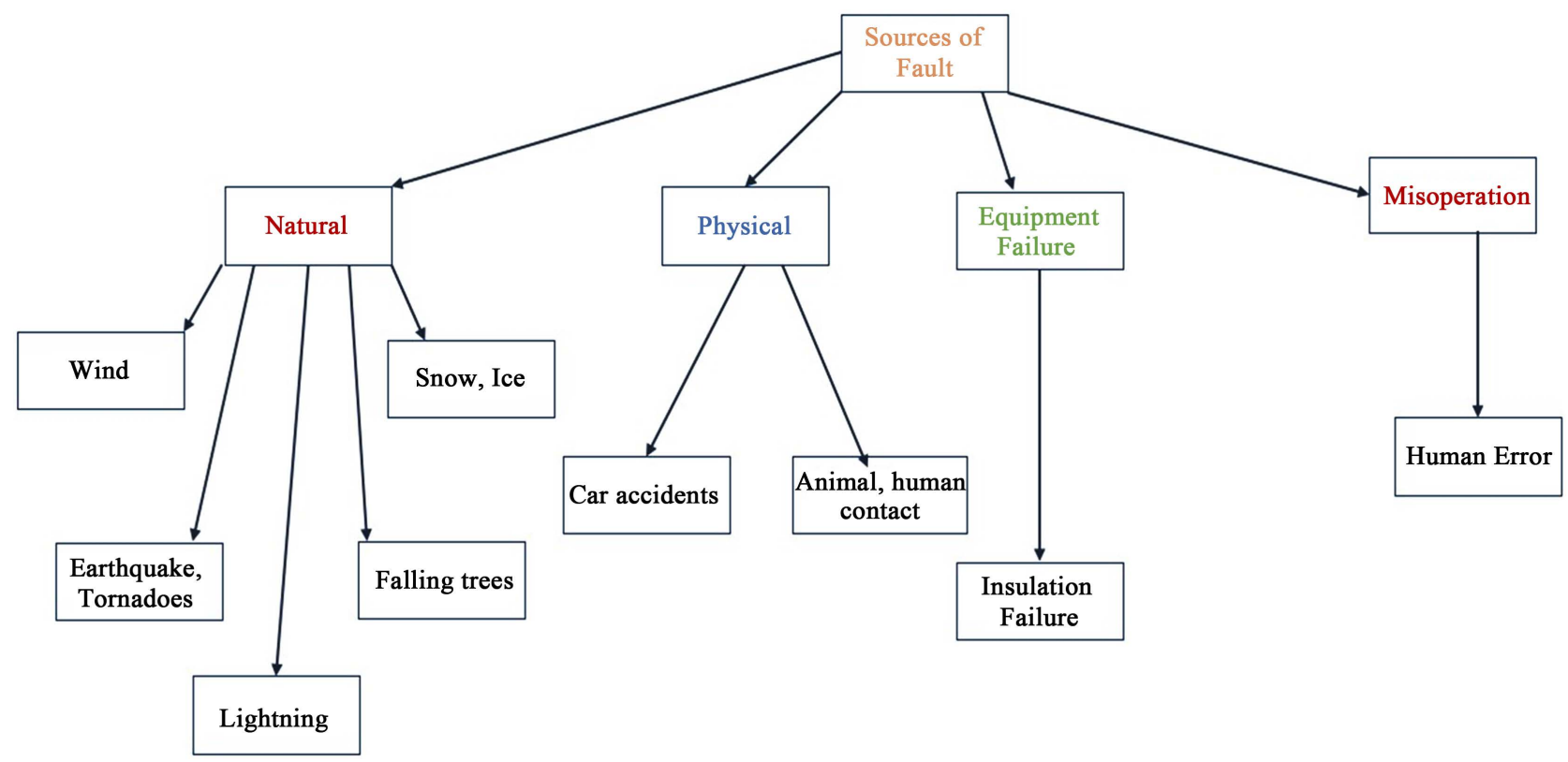

Figure 4. Main sources of faults. 
Table 3. Fault statistics based on power system elements.

\begin{tabular}{cc}
\hline Power System Element & Probability of Faults (\%) \\
\hline Overhead Lines & 50 \\
Underground Cables & 9 \\
Transformers & 10 \\
Generators & 7 \\
Switchgears & 12 \\
CT, PT, Relays etc. & 12 \\
Total & 100 \\
\hline
\end{tabular}

\section{Challenges in Distributed Generation Protection}

There are various challenges which are encountered in distributed generation protection. They are discussed below.

\subsection{Variations in Short Circuit Levels}

As active distribution networks operate in two different modes, this creates a big challenge. In the grid-connected mode, the fault current is supplied by the utility grid as well as the DG source. The current level is enough to trip any protection device and associated relay. In islanded mode, inverter-interfaced DG limits the fault current to about two times the rated current because of the low thermal overload capability of the inverter. Hence, it is difficult for a protective relay to respond accurately and correctly to that current because in traditional radial systems, the protective devices are normally configured based upon the magnitude of the fault current. For correct operation of over current relays, the fault current should be at least 5 - 10 times the nominal rated current. This issue highlights the need for a suitable protective method [29]. Moreover, renewable DG sources (wind, solar) are intermittent; meaning they supply the fault current if, and only if, they are in the "on" state. Thus, the magnitude of the fault current keeps altering depending on the operation mode, type of DG and number of DG sources. Therefore, it is problematic to predict fault current in an accurate way [30]. Moreover, when the fault occurs downstream of the PCC, both the main grid and the DG source contribute current as depicted in Figure 5. The relay located upstream of the DG source measures fault current provided by the upstream source. The actual fault current is different. Consequently, the relay will not work accurately; and this will lead to coordination issues [31].

\subsection{False Tripping}

False tripping, or sympathetic tripping, takes place when the fault current in a feeder is complemented by the fault current produced by the DG source in the adjacent feeder connected to the same substation. In such cases, the relay of the feeder might disconnect the circuit causing a grave problem known as false tripping [32] [33]. Such incorrect (or false) tripping of a healthy feeder with DG 


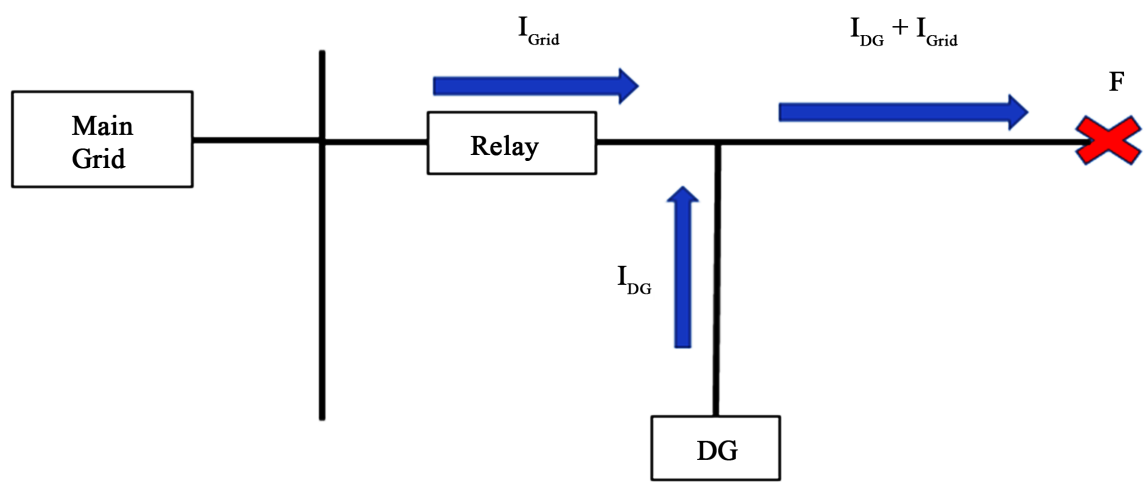

Figure 5. Variations in short-circuit levels.

usually happens when a synchronous generator is employed as a DG source as the fault can feed and sustain the fault current. Figure 6 depicts the scenario of false tripping. As evident from the figure, the relay experiences current from the DG as well as the main grid. Therefore, additional current passes through the relay. If the relay is set to pick up, for instance, 2 p.u., with the fault current from the grid only, the inclusion of DG makes the relay trip much earlier as DG also supplies fault current. In other words, the DG contribution to the fault current can exceed the pick-up level of the relay which can result in a trip of the healthy feeder before the actual fault is cleared. This issue can also be termed as a selectivity issue. Distributed generation supplies the majority of the fault current when the DG source and/or the fault are located near the substation. This phenomenon is common in weak grids with long feeders, which are protected by definite over current relays. In this situation, the settings of the protective relays must guarantee that faults at the end of the feeder are also detected, which lead to a moderately small pick-up current. False trips can cause various issues in active distribution networks including an unnecessary outage of non-critical loads (which are normally disconnected because of islanding) and deterioration of power quality.

\subsection{Blinding of Protection}

Pickup current of an over current relay is set in such a manner that it is larger than the rated current of the feeder but less than the minimum short circuit current of the protected zone. When the DG unit and the substation are feeding the fault in parallel, the fault current detected by the over-current relay is reduced (due to the DG contribution to the fault current). This causes the relay to under reach its required protective zone. In other words, the relay is "blind" to the fault [34] [35] [36]. This phenomenon is shown in Figure 7. Assume that the DG source is connected at a distance "d" from the grid and the fault takes at a distance "l" from the grid. The distance between fault point and DG interconnection point "P" is represented by (1-1). Let $Z_{s}, Z_{g}$ and $Z_{L}$ denote the impedance of the utility grid, DG unit and distribution line respectively. Thevenin's equivalent circuit of the network can be represented as shown in Figure 8. 


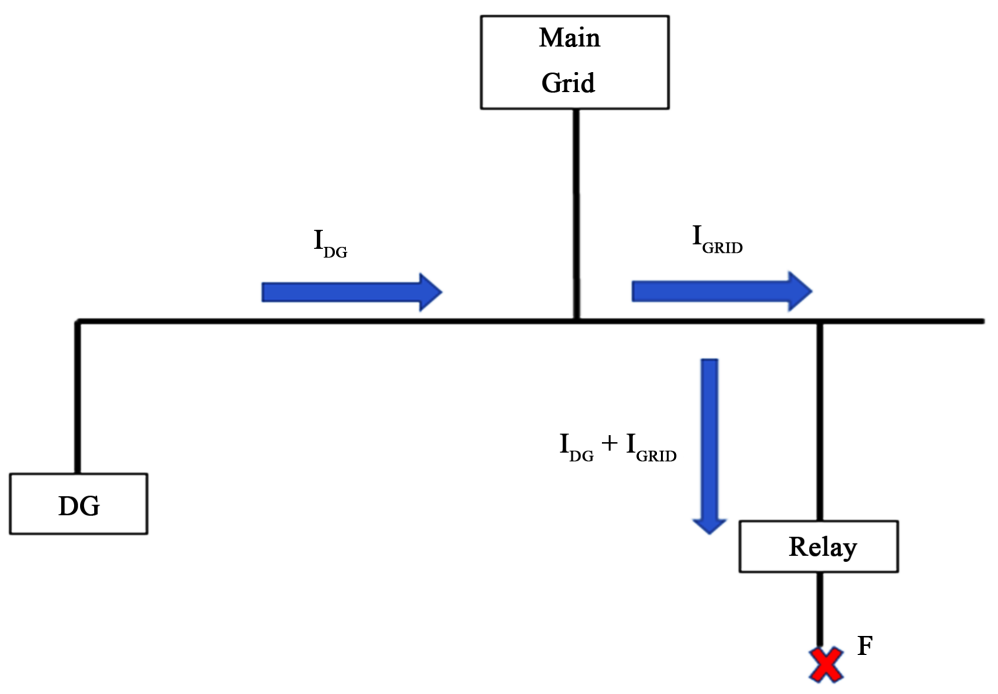

Figure 6. False tripping due to fault "F".

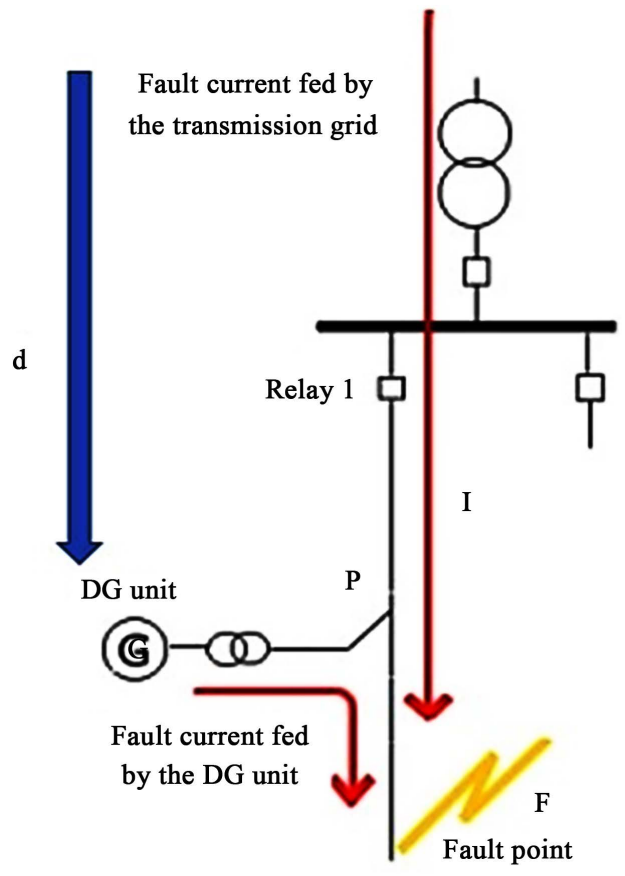

Figure 7. Blinding of protection due to fault "F".

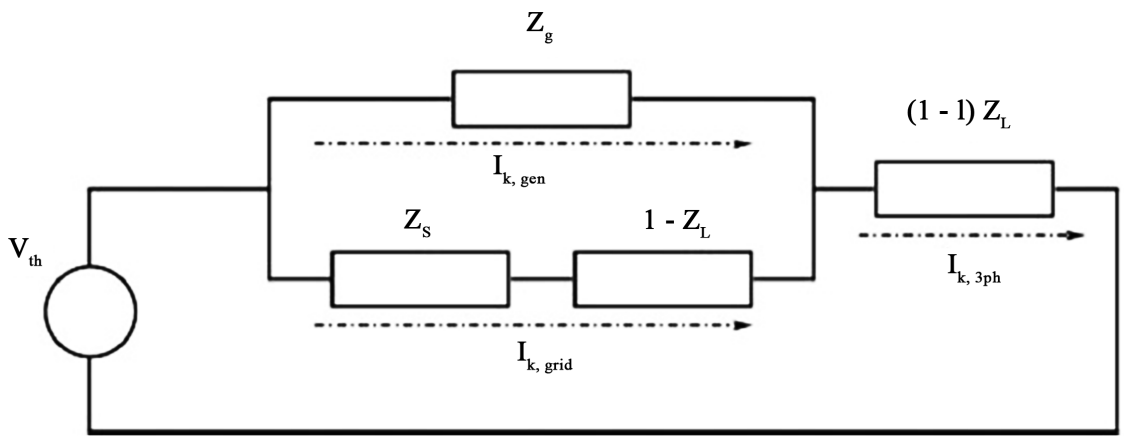

Figure 8. Thevenin equivalent circuit. 
The venin impedance, denoted by $Z(T H)$, is calculated as given by Equation (1)

$$
Z(T H)=\frac{Z_{g}\left(Z_{s}+l \cdot Z_{L}\right)}{Z_{s}+l \cdot Z_{L}+Z_{g}}+Z_{L}(1-l)
$$

Fault current contribution from the grid, denoted by $I(G)$, is given by Equation (2)

$$
I(G)=\frac{Z_{g} \cdot I k}{Z_{s}+l \cdot Z_{L}+Z_{g}}
$$

where;

$$
I k=\frac{V t h}{\sqrt{3} Z(t h)}
$$

The contribution of the fault current by the grid varies nonlinearly with the location and the size of DG source. Therefore, in a microgrid, when a fault occurs at the lower end of the feeder, the grid impedance will be as large as the DG impedance. Consequently, the short circuit current will be less than the pickup value of the current of the feeder relay (Relay 1 in Figure 7) in the LV network as the relay will fail to detect the fault and will subsequently cause the total protection system to malfunction.

\subsection{Unsynchronized Reclosing}

When a DG source is connected to a network, the two energized systems get connected with the aid of a recloser. If the connection is completed without taking synchronism into account, severe damage can occur to delicate power equipment and the DG source [37]. Figure 9 shows the PCC, designated as "C", where the DG source is to be connected to the main grid. The frequencies, phase angles and phase sequences of the DG source and the existing system must be the same for synchronism to accurately take place. Moreover, the voltages at the DG source terminals need to be the same as that of the main grid before the two systems are connected at "C".

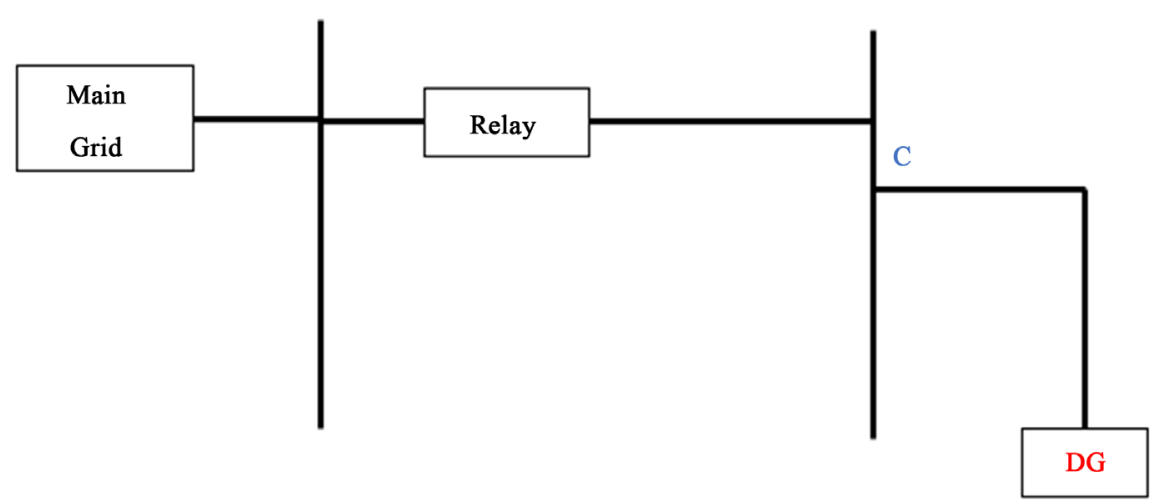

Figure 9. DG interconnection with the main grid. 


\subsection{Selection of a Protection Device}

The choice of a protection device depends on the required speed of operation, voltage level, and availability of sufficient fault current. This selection might range from a miniature circuit breaker to a high speed solid-state relay. A significant consideration for high-speed response of a protective device is the possible loss of DG stability due to a fault on the main grid or the bus to which the DG source is connected. Directly-coupled DG sources are the most vulnerable in this aspect as they are quite sensitive to voltage dips caused by faults and may jeopardize the stability of the DG and hence, the entire network [37].

\subsection{Single-Phase Connection}

Some DG sources input single phase power into the distribution grid, for instance, small photovoltaic (PV) systems. This badly disturbs the balance of the three-phase current as unbalanced neutral current rises. This leads to the flow of stray earth currents. It is essential to restrict this current to avert the issue of overloading and to ensure safety of personnel [38].

\subsection{Change in Fault Impedance}

When a DG source is introduced into the distribution network in parallel, the net impedance of the system will decrease. This can cause very high fault current in the network. These currents will be much higher if the DG source is a synchronous generator. In the case of improper protection coordination, these fault currents can proliferate throughout the network and cause a lot of damage to various components [39].

\subsection{Recloser-Fuse Coordination}

The main operating philosophy of feeder protection is that the fuse should operate only for permanent faults within its reach. For transient (temporary) faults, however, the recloser should disconnect the line and give the line a few chances (depending on the pre-set count) to clear the fault. When the DG units are connected to a radial distribution feeder, fuse-recloser coordination is lost. It is probable that the fuse "sees" more fault current, as compared to recloser, and may melt before the recloser operates. This problem badly affects the overall reliability of the network. Referring to Figure 10, it is evident that for accurate recloser-fuse coordination, the fuse should operate after the recloser's "fast curve" and before the recloser's "slow curve" at the instant of fault current " $I_{\text {fault }}$ ". However, if the situation shown in Figure 11 occurs, the fuse-recloser coordination is lost as the fuse "sees" more current compared to the recloser due to the DG source “G” [40] [41].

\subsection{Reverse Power Flow}

One of the major challenges to protecting an active distribution system is because power can flow in both directions in each feeder of the grid as power 


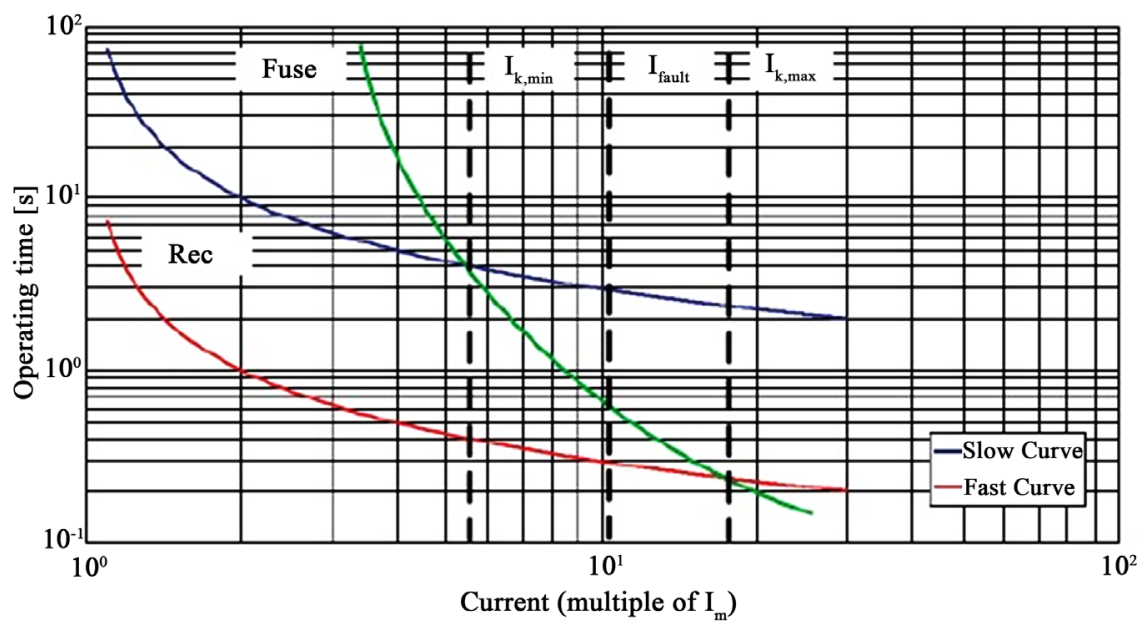

Figure 10. Fuse-recloser coordination curves.

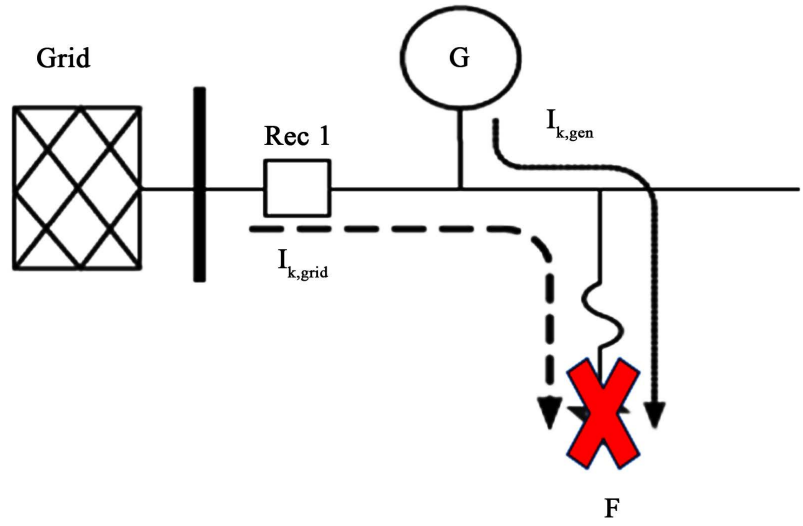

Figure 11. Fuse-recloser miscoordination due to fault "F".

sources are located on both sides. This phenomenon is depicted in Figure 12. Reverse power flow is also known as back feeding. It is important to mention that power flow also changes its direction, when local generation is greater than local consumption. Power quality issues can arise due to this reverse flow of power, that, in turn, leads to large variations in system voltage. Due to reverse power flow, conventional overcurrent protection is not applicable. This protection only applies to situations where fault currents flow in one direction. The reach of impedance relay relies on the distance between the relay location and the fault point. If a fault occurs downstream of the DG bus, impedance measured by the relay located upstream is higher than the actual fault impedance. This affects the grading of relays and results in delayed operation. In some cases, depending on the severity of the fault, the relay does not operate at all. Reverse power flow also causes problems in accurately coordinating protective relays. Due to bidirectional currents, settings of relays will be affected. Conventional differential protection will also suffer as it will be unable to distinguish fault current direction. Thus, a conventional differential scheme may require pilot communication for accurate detection of faults which is expensive [42]. 


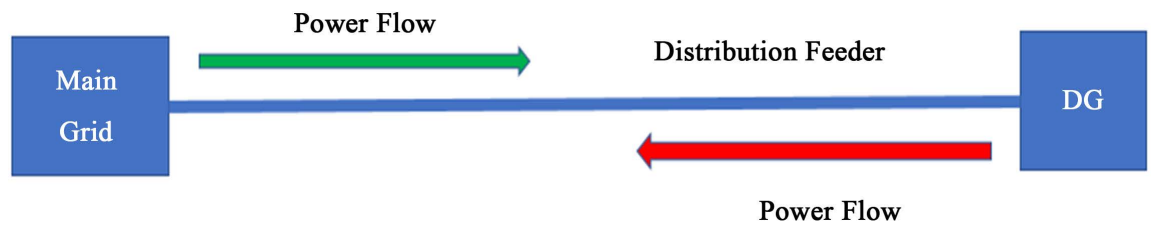

Figure 12. Reverse power flow due to DG.

\subsection{Loss of Mains (LOM)}

This issue refers to the phenomenon that occurs when the distribution grid disconnects from the main utility grid, but remains connected to part of the load in the utility grid. This can occur for two reasons: a utility grid fault, or a problem in the circuit breaker operating mechanism which is connected to a utility source. During this situation of unintentional islanding, the life of the person attending the fault, is at stake since islanding is not detected. This problem also leads to uncontrolled frequency and voltage and non-synchronized reclosures which, in turn, can damage customers' sensitive equipment [43].

\subsection{Device Discrimination}

In a power network containing power sources at only one end of the system, fault current declines with increases in distance as the impedance increases. For discrimination purposes, this change in the magnitude of the fault current is utilized. In the case of an islanded distribution grid with an inverter-interfaced DG source, fault current is restricted to a much lesser value compared to the value obtained with directly coupled DG. The conventional current protection scheme, which utilizes the disparity in fault current magnitude for discrimination, is not applicable in this situation [39].

\subsection{Grounding}

In references [35] [44] [45] [46], probable grounding problems due to more than one ground current path are pointed out. If a DG unit is connected through a transformer which is configured as a grounded delta-wye, ground faults on the utility line will originate ground currents in both directions, from the fault to the utility transformer and to the DG transformer. This is typically not considered in distribution system ground fault coordination.

Although, all the above-mentioned challenges inhibit accurate operation of protection systems; false tripping and blinding of protection are the most significant ones as they directly affect the relay settings. Unfortunately, these two issues are also the most challenging due to intricacy in updating the relay settings corresponding to different levels of fault currents.

\section{Possible Solutions for Protection Issues}

Many research papers mention the problems related to DG protection; however, only a few suggest some solutions. Some possible solutions, to the challenges 
encountered in protecting active distribution grids, are summarized below.

\subsection{Protection of Inverter-Interfaced DG Units}

Traditional protection systems are unable to provide accurate protection for inverter-interfaced DG sources as the fault current produced by these DG sources is of much lesser quantity. The thermal rating of the inverter limits the current. One possible solution can be to use a higher rated inverter which can provide just enough current for a protective relay to trip in the event of a fault [31] [42]. Although, this solution is expensive, it will solve the problem.

\subsection{Differential Protection Using Communication}

The traditional overcurrent protection is unable to provide accurate protection as it cannot differentiate between inverter-interfaced DG sources and overload current. To correctly clear the fault in islanded mode and to enable selectivity, it is essential for various DG sources to communicate with one another in an effective manner. Pilot wire differential communication can be utilized to solve this problem. This enables the information at both ends of the line to communicate with each other [42]. A simplistic view of pilot relay is shown in Figure 13.

\subsection{Balanced Combination of Various Types of DG Sources}

To properly protect the distribution grid in islanded mode, synchronous generator DG sources can be used in combination with inverter-interfaced DG sources. In this manner, there will be enough fault current for the relay to trip [42].

\subsection{Symmetrical and Differential Current Components}

Symmetrical components can be utilized to protect the distribution grid against unsymmetrical faults, such as single line-to-ground and line-line faults. The single line- to-ground and line-line faults can be detected using zero sequence and negative sequence components of current, respectively. Nevertheless, zero and negative sequence components of current are also non-zero when a DG source is operating under normal conditions. This is since a DG-connected distribution network might generally include single-phase loads or three-phase unbalanced loads [47].

Bus 1

Bus 2

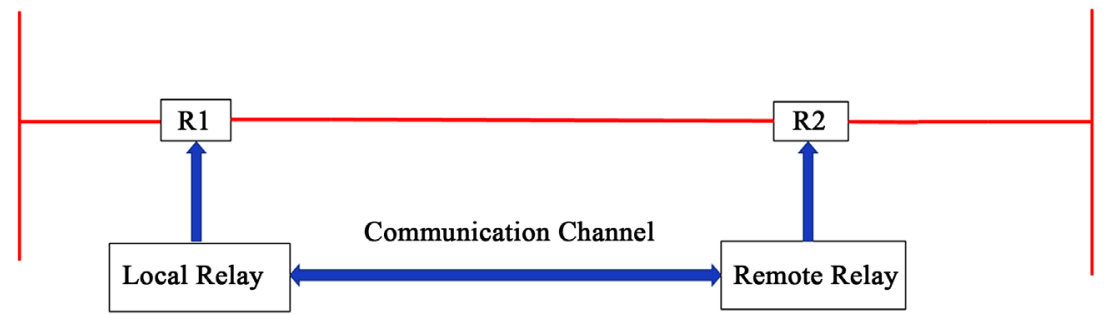

Figure 13. Pilot relay differential communication. 


\subsection{Fault Current Limiter (FCL)}

Fault current limiters can be very useful in mitigating the effects of DG sources on the main grid. Basically, they consist of reactors having a large reactance and placed in series with the line connecting the main grid and the DG source, as shown in Figure 14. The large reactance plays a vital role in minimizing the fault currents contributed by the DG sources. However, the most difficult task here is setting the correct reactance. If it is too small, fault currents of DG will affect the main system, and if it is too large, it will suppress the currents to an extent that a protective relay cannot trip accurately for the desired fault [48].

\subsection{Energy Storage Devices}

As mentioned earlier, fault current in islanded mode in the presence of inverterinterfaced DG sources is constrained to about two times the rated current due to thermal limitations of the inverter. A possible solution would be to use energy storage devices, such as large batteries, flywheels, and super capacitors, to provide sufficient current for the relay to operate. However, employment of these devices will incur a lot of expense; and most importantly, this technique will largely rely on islanding detection technology [48].

\subsection{Adaptive Protection}

To deal with the varying modes of operation of an active distribution grid, adaptive protection is very useful [49]. When there is a variation in system topology, the relays automatically update their values from the database of stored values [50] [51]. A conceptual model of adaptive relaying is shown in Figure 15.

\subsection{Smart Protection}

Reference [52] suggests a novel concept for smart protection. Smart protection relies on the fact that a DG source integrated with the main grid network should possess its own protection scheme at PCC to transfer electrical power. The fault location isolation and service restoration (FLISR) application is a significant advancement in smart protection as it enables distributed utilities to devise advanced protection techniques. Figure 16 shows the time line for fault investigation without FLISR, and the delay can clearly be seen. FLISR produces an instant

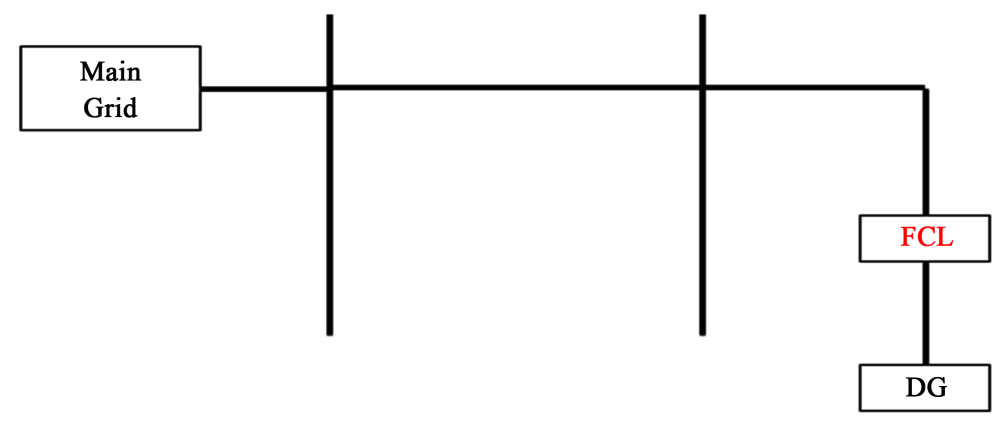

Figure 14. Use of FCL to limit DG fault current. 


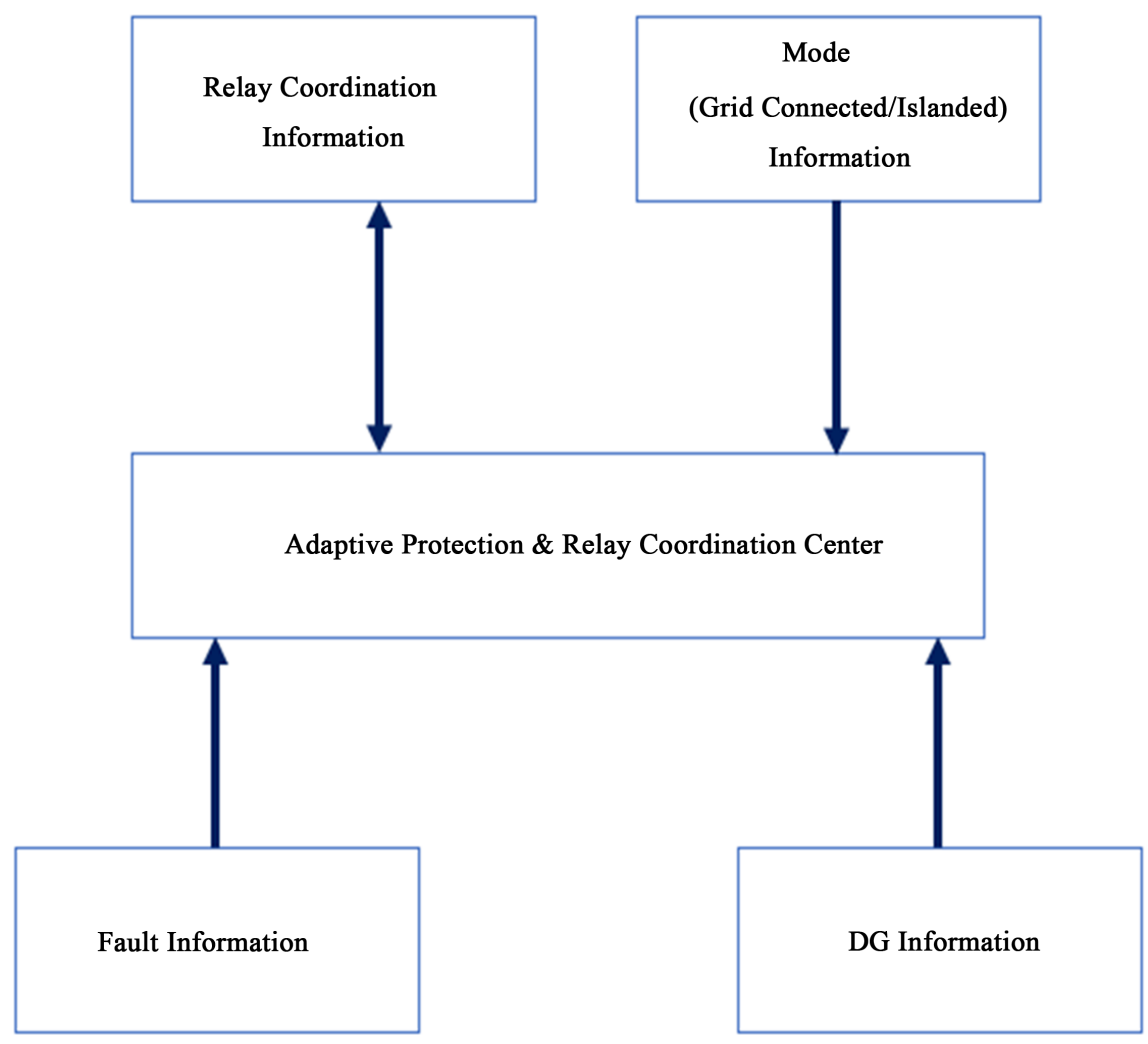

Figure 15. Adaptive protection schematic.

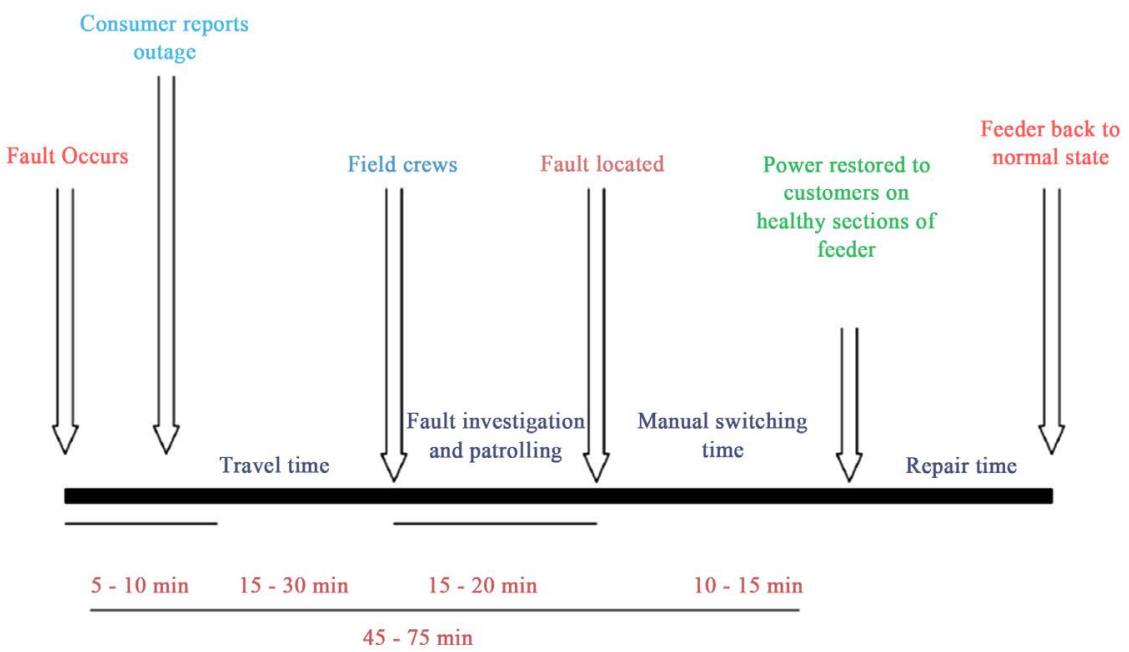

Figure 16. Timeline for fault investigation without FLISR.

exchange strategy for restarting sections of the distribution circuit that have been tripped due to an unending feeder fault. Once this strategy is produced, FLISR can enforce the plan to restore service where viable, usually in about sixty seconds, after the original fault has occurred. The FLISR application automatically detects the fault occurrence and finds the fault between two intermediate switches. Consequently, control commands are sent to open the switches to restore service to non-faulted segments of the feeder. This contemporary technology 
permits these actions to be accomplished without manual involvement.

In smart protection, there are numerous control functions, including regulated power flow on feeders, regulated voltage at the interface of each DG source, and load sharing when the system is operating in islanded condition. These functions can help in solving some issues related to protection of active distribution networks. For instance, a regulated voltage function will ensure that if a fault occurs at any bus, the voltage at other buses in the network will remain within the nominal range. Reverse power flow detectors will ensure that power flows only from the main grid to the DG source and not vice versa. Unsynchronized reclosing can also be tackled. Smart protection can trigger a synchronism checker at the instance of DG interconnection. Moreover, FLISR can enable switched FCLs at the instant a fault occurs. In this way, fault current contribution due to DG sources will be restricted; and this will aid in proper operation of protection relays. A generic outline of FLISR is described below [52].

\subsubsection{Fault Detection}

Fault location isolation and service restoration control is adjusted in a manner such that it operates when a short circuit fault occurs. If the feeder is deenergized due to manual switching operations, the FLISR application does not operate. This procedure can be attained by placing multiple fault detectors to activate the FLISR function. Usually, a microprocessor-based relay or intelligent electronic device (IED) is connected in grid stations to supply a signal to the FLISR application for proper operation.

\subsubsection{Fault Location}

In the next step, the faulty segment on the feeder needs to be located. There are diverse sections on the FLISR application, which are surrounded by controlled switches. These switches contain the faulted circuit indicator (FCI) that calculates if fault current has passed through the switch lately. This specifies if a fault is located farther down from the grid station and employs the FCI status and network topology to find the faulted area.

\subsubsection{Fault Isolation}

In this step, the FLISR application issues control commands to open the switches; required to totally isolate the faulted segment of the feeder based upon the fault location examination. The FLISR application halts all control actions until the routine reclosing sequence is accomplished and ensures that feeder reconfiguration by the FLISR application is achieved. When the seconditions are met, the FLISR application follows the permanent fault to operate.

\subsubsection{Service Restoration}

This is the last step performed by the FLISR application, to isolate the faulty segment of the feeder. It tries to restore the service to the maximum possible healthy segments of the feeder by employing the normal source of supply to the feeder. 


\subsection{Centralized Protection}

In centralized protection, a microgrid consists of one central unit. The LV microgrid is connected to the main grid via a delta/star transformer. Normally, four protection devices $\left(\mathrm{PD}_{1}, \mathrm{PD}_{2}, \mathrm{PD}_{3}\right.$ and $\left.\mathrm{PD}_{4}\right)$ are used as shown in Figure 17. $\mathrm{PD}_{1}$ (voltage and frequency relay) is located at the PCC, $\mathrm{PD}_{2}$ (directional overcurrent relay) is in the feeder, $\mathrm{PD}_{3}$ and $\mathrm{PD}_{3 \mathrm{a}}$ (non-directional over-current relays) are in service connections, and $\mathrm{PD}_{3 \mathrm{~b}}$ (overcurrent protection with fuses) and $\mathrm{PD}_{4}$ (voltage and frequency relay) are located in the DG sources. A microgrid management system (MMS) is employed to see the microgrid status and to adjust the rating of the protective devices. The protective devices $\mathrm{PD}_{1}$ and $\mathrm{PD}_{2}$ must operate in the order of milliseconds, especially during islanded operation. The purpose is to adjust the operating curve for the protection devices for both grid-connected and islanded modes. The MMS conveys the status of the microgrid (grid-connected or islanded) to the protection devices. Depending on this status, the protection devices match the measured parameter with the operating curves and, consequently, issue a suitable trip signal [53].

\subsection{Rate of Voltage Change}

Loss of mains detection is possible because of the rate of change in voltage. This is discussed in [33]. Normally, voltage changes are much slower in large, interconnected power networks. If the distribution system gets in islanded mode, a rate of voltage change happens that is remarkably larger than during grid-connected operation. Thus, the voltage rate of change can be utilized to sense is landing operation. A flaw of this technique is its sensitivity to network disturbances other than LOM.

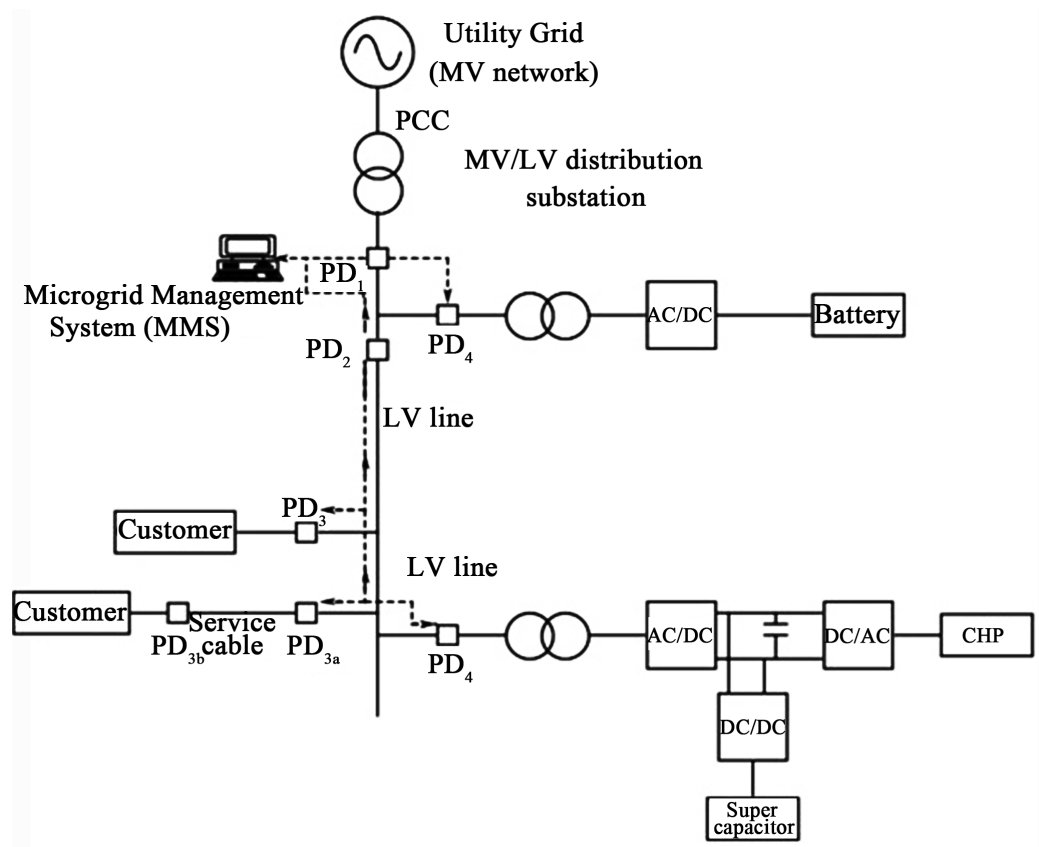

Figure 17. Centralized protection of a microgrid. 


\subsection{Rate of Change of Frequency (ROCOF)}

The frequency in the islanded mode varies swiftly due to active power imbalance. The conforming frequency slope (or gradient) can be utilized to sense loss of mains. When this gradient is greater than a specific limit, relays are tripped. Characteristic pick-up values are adjusted in the range of 0.1 to $1.0 \mathrm{~Hz} / \mathrm{s}$, and the operating time is somewhere between 0.2 and $0.5 \mathrm{~s}$. An issue with ROCOF protection is the undesirable tripping that results from frequency excursions due to a loss of bulk supply, for instance, faults in the main grid [54] [55].

\subsection{Disconnecting DG Sources}

Disconnecting all DG units for all temporary faults will make the power network unreliable, particularly because most of the faults occurring in the distribution system are temporary [56] [57] [58]. The DG sources must be terminated rapidly once the fault has been sensed to protect the sensitive power electronic devices in equipment, such as converters and inverters. The termination process is simple and swift: 1) the switching frequency is comparatively high compared to the power frequency and, 2) when the current reaches about two times the rated current, the switching signals are stopped [28].

\subsection{Artificial Intelligence Techniques}

Due to the intricacy of active distribution systems and numerous uncertainty factors that are problematic to address using conventional protection techniques, a knowledge-based method is suggested for finding faults. Normally, this technique needs information, such as feeder measurement, substation and feeder switch status, data provided by protective devices installed along the feeders, and environmental conditions. This information can be examined using artificial intelligence methods. Some artificial intelligence-based methods, that have been used in fault location, in active distribution systems, are described below [59].

\subsubsection{Artificial Neural Networks (ANN)}

A generic flowchart for ANNs is shown in Figure 18.

In [60], the ANN employs two distinct approaches to finding fault distance in distribution feeders using one- and two-end measurements. The scheme uses cascade correlation for fault detection, and both approaches perform equally well in accurately identifying fault location. The design has the advantage that cascade correlation uses fewer epochs (forward passes) and fewer hidden layers when compared to multilayer perceptron (MLP).

In [61], a technique to sense high impedance faults for nonlinear arcing is suggested. The method evaluates lower order voltage and current harmonics. An ANN-based design that does not consider the fault inception angle is suggested in [62]. The scheme considers fault resistance and does not rely on fault inception angle. It uses the fundamental components of pre-fault and post-fault positive sequence components of voltage and current as inputs for approximating 


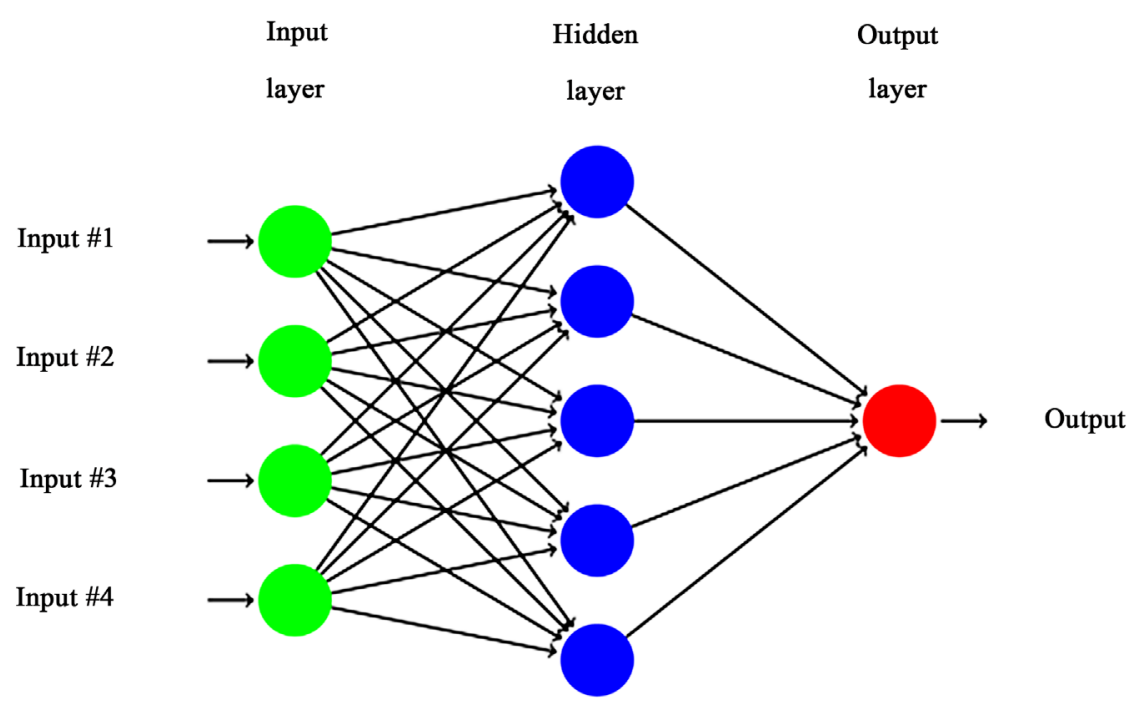

Figure 18. Generic ANN flowchart.

the fault location. The method employs MLP with a back propagation training algorithm and the Levenberg-Marquardt optimization method.

A neural network was employed to help the network operator in a fault section estimation control center in [63]. The research was based on the operation information of circuit breakers and associated protection devices. For diagnosis purposes, the protection of transformers, bus bars and distribution lines was modeled with two types of ANN: MLP and general regression neural networks (GRNN). The test results show that the ANN can accurately handle the variations in a system network in real bulk power systems without having the need to train the networks again.

\subsubsection{Fuzzy Logic}

In fuzzy set theory, the idea of possibility is used rather than the concept of probability. Possibility is defined as a number between one (completely possible) and zero (totally impossible). On the other hand, probability is a suitable measure of uncertainty if statistical information is available. In uncommon circumstances, where no statistics are available, an expert may be able to express degrees of confidence in various hypotheses. A generic flowchart for fuzzy logic is shown in Figure 19.

A fuzzy logic-based classification scheme is suggested in [64] [65] [66], which identifies the fault type in distribution systems connected with DG. In [64], higher order statistics are established to extract the characteristics of a fault signal and to categorize the fault employing fuzzy logic. Fault identification using line current measurement of three phases is recommended in [65]. Later, this method was presented in [66] for detecting unsymmetrical faults in unbalanced systems. The fuzzy system is used in [67] to identify the fault type and fault location in double circuit lines. The method categorizes series, shunt, and simultaneous series-shunt faults. Simulation results indicate that the fault location error percentage is within $1 \%$ for series faults and is up to $5 \%$ in shunt faults. A method 


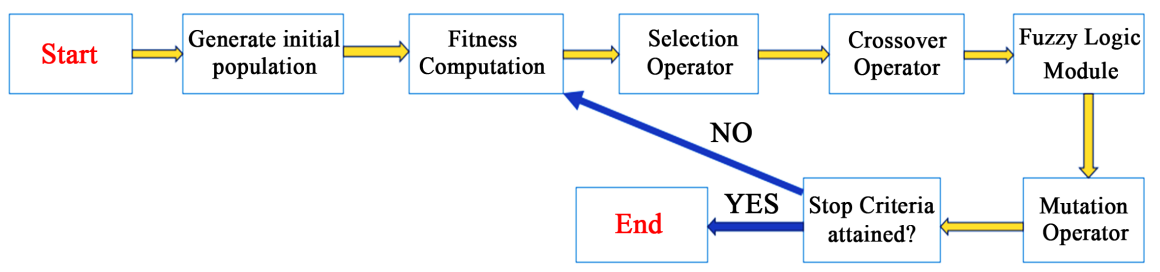

Figure 19. Generic flowchart of fuzzy logic.

for fault detection and classification based on fuzzy logic and programmable automation and control (PAC) technology is proposed in [68]. The three-phase alternating current, zero sequence and positive sequence current data are produced and processed directly for relaying. The simulation results imply that the scheme devised can correct tripping action and can provide real time, automatic protection. Although, the fuzzy-logic-based scheme is reasonable, it has a disadvantage in computing the global minimum using fuzzy membership functions. Moreover, feature definitions and extractions must be boosted for the classification algorithm.

\subsubsection{Genetic Algorithm (GA)}

A genetic algorithm (GA) is an intelligent method that can be utilized for fault location. The technique searches the possible fault locations through selection, crossover and mutation operations to recognize the exact location. The flowchart for a GA is shown in Figure 20.

A method to approximate a faulty segment using GA is developed in [69]. In this work, the faulty section approximation is considered as an optimization problem. The objective function is identified employing Hebb's Rule and using a continuous genetic algorithm (CGA) optimization for faulty section identification. The objective function decreases the time required by a CGA to detect the faulty section. Moreover, the suggested technique uses less storage and is faster than binary GA.

A novel method using GA is presented in [70], which divides the active distribution systems into main branch and individual regions. The independent regions are sensed using the fault current and GA is utilized for fault location for the chief branch and fault independent regions. This scheme is only applicable for a single kind of fault. A fault location method using GA for distribution feeders is suggested in [71]. It uses line parameters at both terminals of the feeder to recognize the fault location. The design was tested with the real fault recording data obtained from the South Grid of China.GA and wavelet transform are used in [72] for fault sorting. The scheme uses three-phase currents at one end of a distribution line for fault detection. The characteristics are extracted using discrete wavelet transform and are treated as inputs to GA. The suggested work categorizes faults with a maximum error percentage of about $7 \%$.

The benefits of the GA technique are that the simulation speed can be improved and the dimensions of likely solutions can be abridged. The drawback is that the results are not reliable over time because in GA, nearly all processes are 


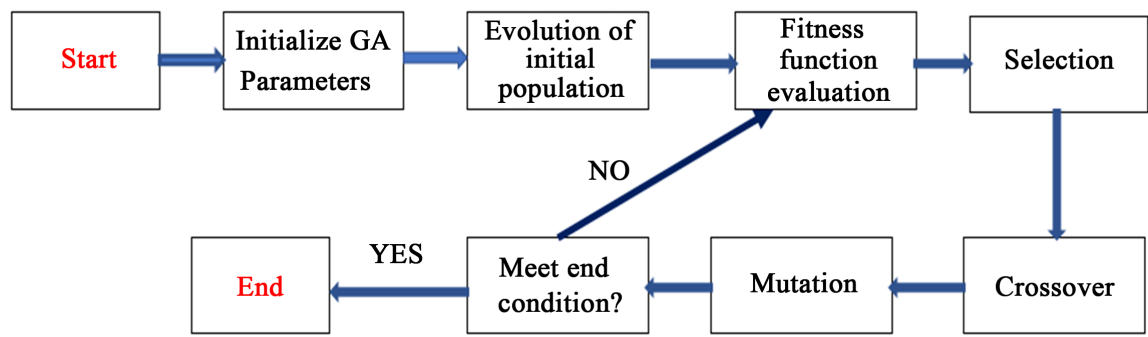

Figure 20. Genetic algorithm flowchart.

random. There is a likelihood that GA may yield inaccurate results; therefore, online analysis using this method may not be suitable.

\subsubsection{Matching Approach}

The matching approach employs a database for identifying fault locations. The scheme compares the measured and simulated data. It observes its environment and takes actions that maximizes its chance of success to achieve an aim. The aim here is to accurately identify fault location. Schematics of the matching approach for fault detection are shown in Figure 21.

Usually, voltage sag or current data are recorded to classify the fault location. In [73], a method for recognizing the faulty segment is presented, where a database is shaped by producing a fault at numerous segments. When a fault takes place, the voltage sag during the actual fault is matched to the one in the database to recognize the faulty segment. The drawback of this design is that only the faulty section is identified; therefore, maintenance personnel need to continually travel along the suspected line segment to accurately determine the exact fault location This is time consuming if the line section is very long and postpones the restoration process. Later, the technique was further enhanced in [74] for calculating the fault distance. The fault distance is computed using a trigonometric equation considering a linear depiction of voltage sag between two nodes. An enhancement was done in [75], considering the voltage sag nonlinear depiction between two nodes. A set of two quadratic equations are framed using voltage phase and distance and current phase and distance for fault distance computation. Nevertheless, this technique is precise for lower fault resistance.

A method in [76] suggests a better faulty section location for three-phase bolted faults by considering multiple measurements. The design presents a novel idea to recognize the faulty section and a ranking technique to prioritize the faulty section. The method is assessed on a11 kV active distribution network containing 5 branches and 43 nodes. The simulation results demonstrate that accurate fault distance is attained by calculating the average of the fault distance from each measurement data. The advantage of the matching approach is that it is cost-effective as it considers only the data associated with node voltage sag. The drawback of this approach is that it relies on the simulated data stored in a database for matching the data with real fault data. The process of creating this database is onerous as it is created by carrying out simulations for fault at every system node. 


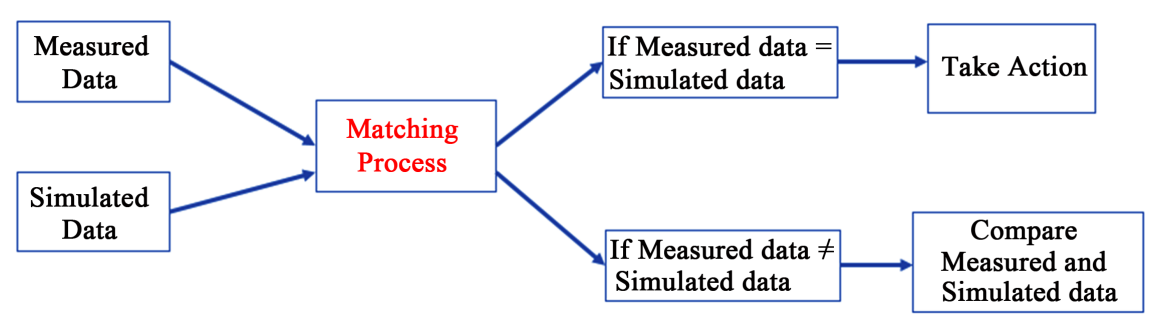

Figure 21. Matching approach schematic.

\subsection{Phasor Measurement Units (PMUs)}

A generic schematic implementation of a PMU is shown in Figure 22 [3]. The receiver section receives the Global Positioning System (GPS) transmission which then delivers a phase-locked sampling clock pulse to the analog to digital converter mechanism. The sampled data is transformed to a complex number which characterizes the sampled waveform phasor. Phasors of the three phases are merged to give a positive sequence measurement. Computation of the discrete Fourier transform (DFT) enables the signal (voltage or current) to be measured.

Phasor measurement units are effective in measuring various electrical quantities (voltages, currents, phase-angles etc.) in real time, and can also be applied to protection of DG-connected networks. The PMUs also have some limitations. The key hurdle in implementing PMUs on a large-scale, active distribution network is the considerable expense associated with the communication network needed to support this technology. Moreover, it is hard to monitor a huge amount of output data. Communication delays should be considered which can lead to delayed action in protection signals. Algorithms are computationally heavy and distortion and harmonics can further deter the results. The use of PMUs may, in some situations, be beneficial for long transmission lines; but they have inadequate capabilities as far as distribution systems are concerned. Lower distances in distribution grids indicate lower amplitude and phase differences between the electric quantities at different nodes. This means more accuracy is required to correctly measure these differences. The high amount of distortion that is usually prevalent in active distribution networks may lead to a need for redefining compliance limits with harmonic intrusions which is beyond the present standard. Lastly, the nonexistence of human supervision requires a high amount of trustworthiness of the information coming from PMUs to utilize them in protection applications [3].

\subsection{Impedance-Based Pilot Protection Scheme}

Although monitoring the variation in impedance could be a reliable way to detect the occurrence of faults in low-fault microgrids, locating faults can be more complex depending on the microgrid topologies. Feeder lengths of typical microgrids are comparatively small; therefore, the impedance seen by various relays, not only the closest relay to the fault, could drop below their threshold values. Furthermore, it is difficult to use conventional distance protection to 


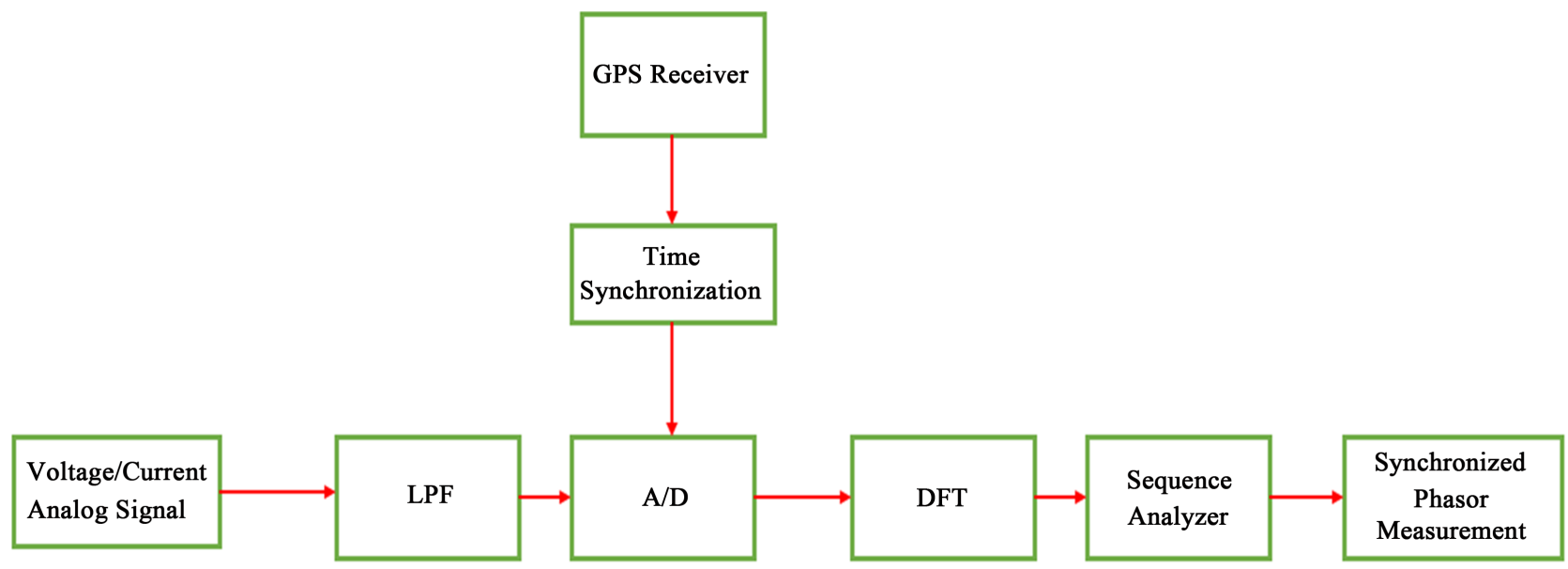

Figure 22. Phasor measurement unit block diagram implementation.

coordinate between impedance relays, based on the values of measured impedance since microgrids exist in different configurations, have tapped feeders, and have no standard locations for fault interrupting devices.For those microgrids where coordination between impedance relays based on the measured impedance is not practicable for the above-mentioned reasons, an impedance-based pilot protection scheme can be used. This protection scheme is based on communication between adjacent relays or, in general, between relays of the same protection zone, to find the fault. Each feeder relay is equipped with an impedance element to sense fault occurrence and a directional element to find the direction of the fault. Different pilot protection logics can be used to find out the location of the fault. For instance, a pilot protection logic based on permissive and blocking signals could be realized as follows [77]:

1) Any relay that detects a fault will:

- Sends a block signal to its reverse zone breakers.

- Sends a permissive signal to its forward zone breakers.

2) Any relay that receives a permissive signal will:

- Ignore the signal if it has detected a fault and the signal is from one of its reverse zone breakers.

- Issue a trip signal to the breaker (fault is in the forward zone) if it has detected a fault and the signal is from one of its forward zone breakers.

- Send back a permissive signal and issue a trip signal to the breaker (fault is in the zone shared by the breaker which sent the original permissive signal) if it has not detected a fault.

The criteria for tripping is meeting one of the following two conditions:

1) Fault detection, no blocking signal and, optionally, receiving permissive a signal.

2) No fault detection, no blocking signal and receiving a permissive signal.

To exemplify the basic operation of the proposed scheme, consider Figure 23. Assume a fault (denoted by $\mathrm{F}$ ) took place on the line segment between relays B1 and B2. Moreover, suppose that impedance elements at all three relays (B1, B2 


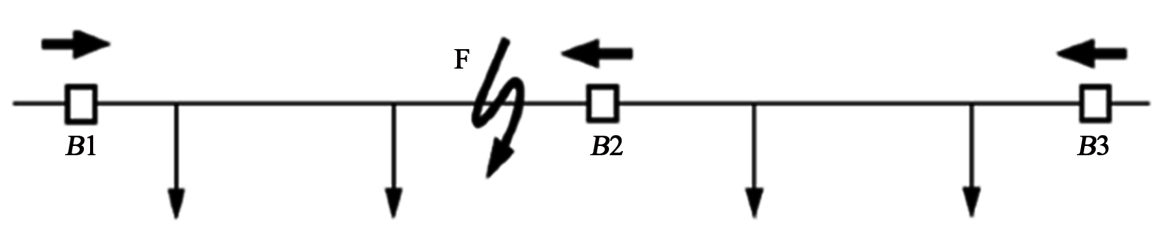

Figure 23. Impedance-based pilot protection scheme.

and B3) detected a drop in their measured impedance below the detection threshold and therefore, declared a fault. Directional elements of these three relays will identify the direction of the fault as shown in Figure 23.

Relay B2 will send a permissive signal to relay B1 and a blocking signal to relay B3. Similarly, relay B3 will send a permissive signal to relay B2 and a block signal to its reverse zone relays (not shown in Figure 23). Consequently, relays B1 and B2, having detected the fault and received permissive signals, will trip their corresponding breakers to clear the fault.

In general, all relays of the same protection zone have to be able to communicate with one another. For instance, for the part of the microgrid depicted in Figure 24, assume that B7 was the only relay that detected the fault F1 based on a drop of the measured impedance at B7. According to the above pilot logic, B7 should send permissive signals to B1, B2, B4 and B8. This could be accomplished via peer communication by sending the permissive signal from $\mathrm{B} 7$ to $\mathrm{B} 2$ and requesting that B2 transfer the permissive signal to B4 and so on. It is significant, however, that while microgrid configurations like the one depicted in Figure 24, are very complex from a protection perspective, they are rather rare in practice today.

\subsection{Protection of Multiple Microgrids}

Currently, some researchers are working towards protection of multiple microgrids. This innovative concept corresponds to a high-level structure- formed at the medium voltage (MV) level and comprises of several LV microgrids and DG units connected to adjacent MV feeders. For grid protection, microgrids, DG units and MV loads under active demand-side management control can be considered to be active cells in this kind of power network [78]. A possible schematic for protection of a multiple microgrid system is shown in Figure 25.

The central autonomous management controller (CAMC) is the heart of the system. It receives fault information from all DG sources connected in the microgrid. The demand management system (DMS) will increase or decrease the demand according to the fault scenarios. The microgrid central control (MGCC) of each microgrid communicates with the CAMC to monitor the status of faults. The remote telemetry unit (RTU) is a microprocessor-based device that transmits telemetric information to the CAMC. The RTU permits synchronized and combined management of individual elements at the LV level, such as microgrids (and conforming microsources, loads and storage devices). Those DG units and loads taking part in active demand-side management approaches, directly connected to the MV grid, may need a devoted communication infrastructure. 


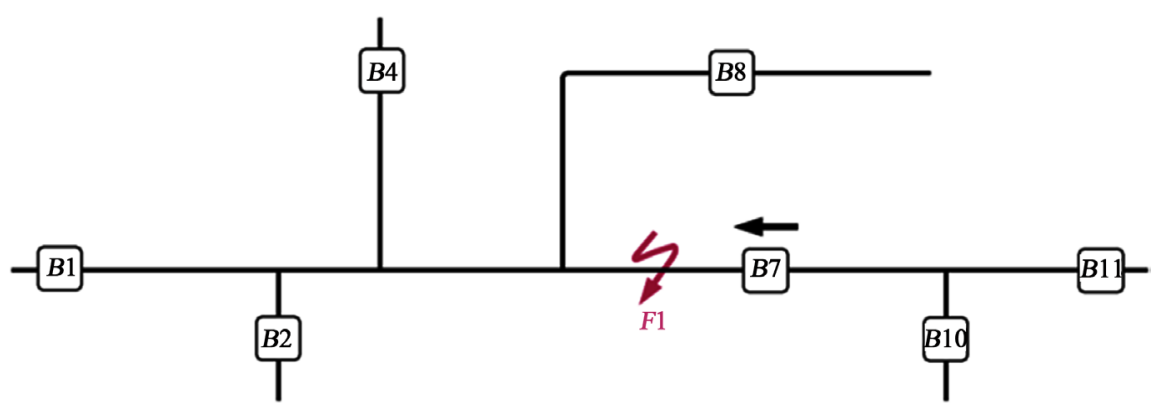

Figure 24. Impedance-based pilot protection scheme.

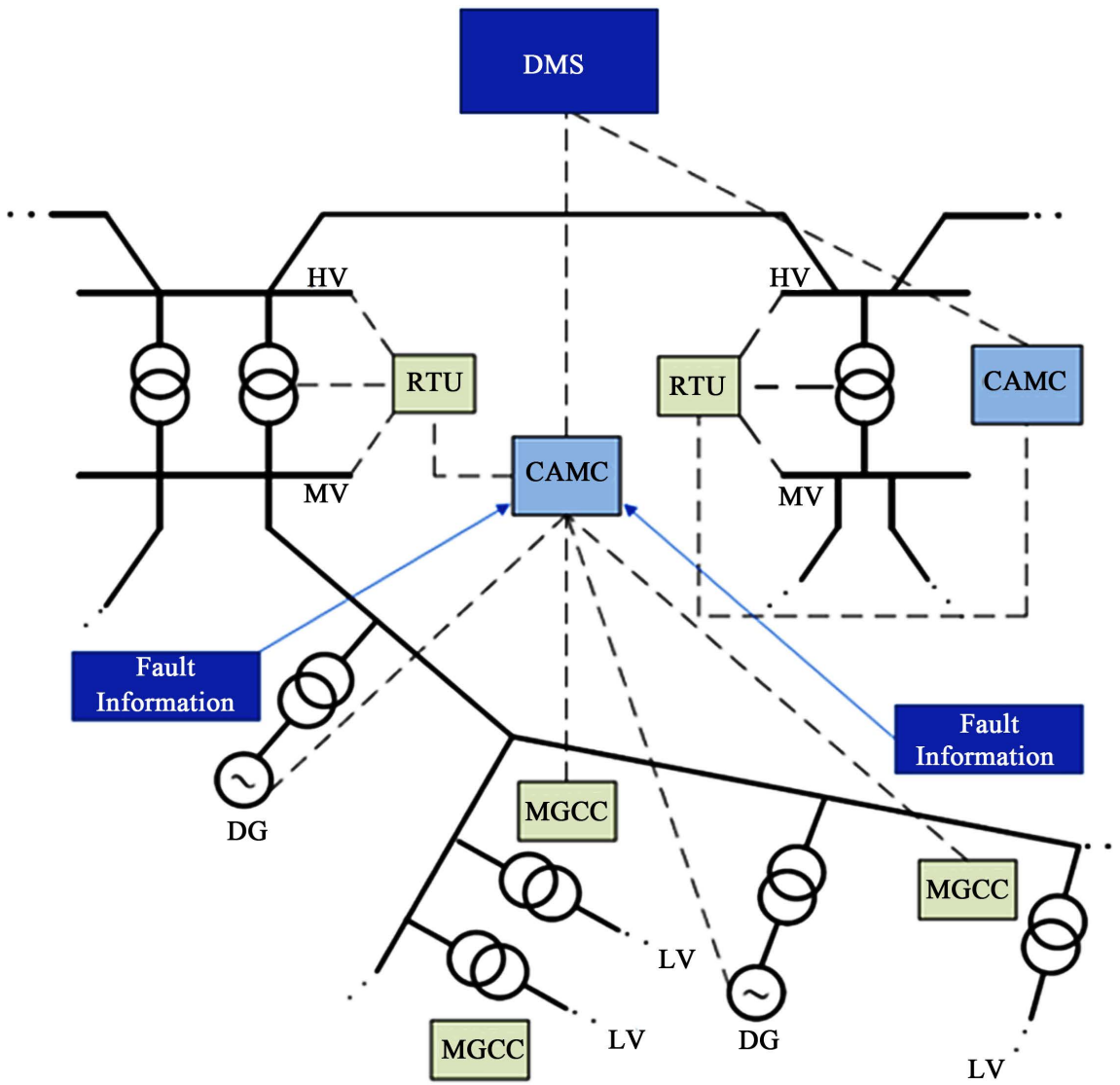

Figure 25. Protection management architecture of a multi-microgrid system.

This local communication infrastructure is the main entity for handling the distribution network in a very efficient way, thereby, making the most of the DG integration, especially renewable-based power sources. The key problem when dealing with protection approaches for multiple microgrid systems is the use of individual protective relays, which must possess a specific amount of autonomy and be able to communicate with each other to devise precise protection actions. A partially decentralized scheme is justified by the incredible upsurge in both dimension and complexity of the network such that the management of a multi-microgrid system necessitates the employment of a flexible and reliable protection management architecture. 
Summary of challenges encountered in DG-connected distribution networks and corresponding solutions is presented in Table 4 and Table 5.

\section{Conclusion and Future Work}

This paper reviewed some major challenges and possible solutions for active distribution networks. The challenges include false tripping, protection blinding, fuse-recloser coordination, changes in fault impedance, unsynchronized reclosing, reverse power flow, loss of mains, selection of a protection device, device discrimination, grounding, single-phase connections, and variations in short-circuit current levels. Possible solutions include the use of higher rating inverter, communication links, energy storage devices, adaptive protection, smart protection, fault current limiter, centralized protection, artificial intelligence techniques, phasor measurement units, impedance-based pilot protection, disconnecting DG sources, balanced combination of numerous DG sources and central autonomous management controller. In addition, fault types and sources were briefly discussed. The present study also pointed out main applications of DG and major issues of microgrids. Based on the work, presented in this paper, it can be concluded that one needs to make a trade-off between various challenges and go with the one that gives the consumer and the company, maximum benefits in terms of less interruptions and disturbances. In other words, there is a need to determine the efficacy of the situation which affects system performance the least, in terms of reliability and dependability. Moreover, there is a dire need to come up with a solution that can tackle these challenges in the most effective way. A possible future direction could be to examine some test distribution systems (including meshed and interconnected) under numerous possible operating conditions and observe variations in critical system parameters (e.g. variations in fault currents, bus voltages etc.) considering the challenges mentioned in this paper. Moreover, a camera can be installed on a pole which can monitor the fault occurrence. The scheme can be implemented on a small test system to observe its accuracy and reliability when applied to protection of DG connected distribution systems as depicted in Figure 26. As evident from the figure, a digital

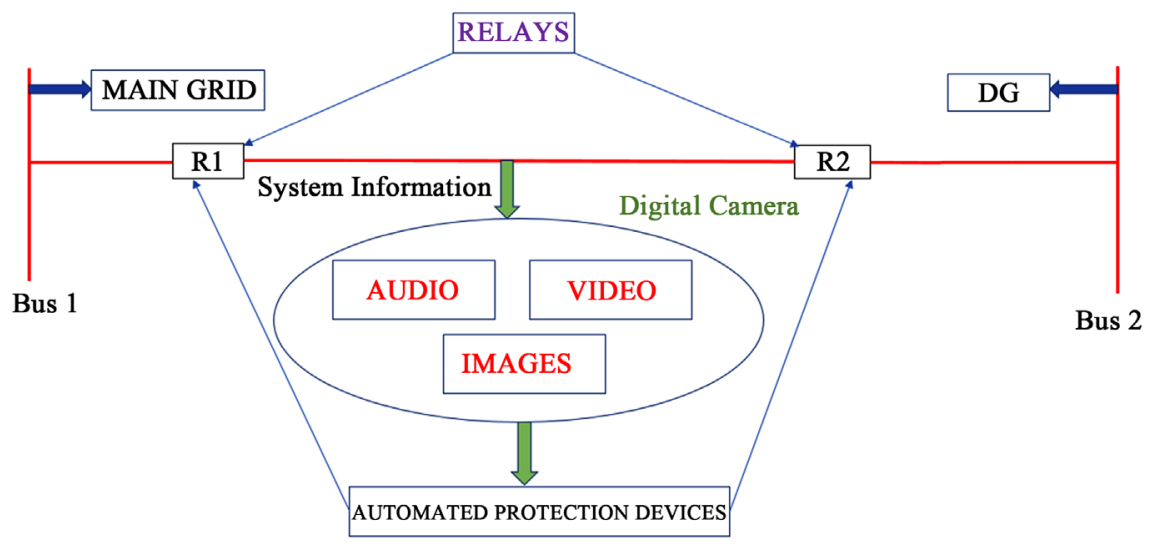

Figure 26. Suggested solution using a digital camera. 
Table 4. Protection challenges of DG and corresponding solutions.

\begin{tabular}{cc}
\hline Challenges & Solutions \\
\hline Variations in Short Circuit Levels & Higher Rating Inverter \\
False Tripping & Communication \\
Blinding of Protection & $\begin{array}{c}\text { Symmetrical and Differential Current } \\
\text { Components/Adaptive Protection }\end{array}$ \\
Unsynchronized Reclosing & Energy Storage Devices \\
Selection of a Protection Device & Adaptive Protection \\
Single-Phase Connection & Rate of Voltage/Frequency Change \\
Change in Fault Impedance & Balanced Combination of Various DG \\
Recloser-Fuse Coordination & Smart/Adaptive Protection \\
Reverse Power Flow & Fault Current Limiter \\
Loss of Mains & Centralized Protection \\
Device Discrimination & Fault Current Limiter \\
Grounding & Disconnecting DG Sources/Adaptive Protection \\
\hline
\end{tabular}

Table 5. Solutions applicable to various challenges of DG protection.

\author{
Artificial Intelligence Techniques \\ Phasor Measurement Units \\ Impedance-Based Pilot Protection
}

Central Autonomous Management Controller/Demand Management System

camera can be employed to monitor real-time information from the system in the form of digital video, audio, and images. The camera can be linked to an automated protection device that trips when it receives a signal from the camera.

\title{
References
}

[1] Shahzad, U. (2015) Control Schemes for Distribution Grids with Mass Distributed Generation. International Journal of Information Technology and Electrical Engineering, 4, 14-18. http://www.iteejournal.org/archive/vol4no2/v4n2_3.pdf

[2] Shahzad, U. (2015) The Need for Renewable Energy Sources. International Journal of Information Technology and Electrical Engineering, 4, 16-19. http://www.iteejournal.org/archive/vol4no4/v4n4_4.pdf

[3] Shahzad, U. and Asgarpoor, S. (2017) A Comprehensive Review of Protection Schemes for Distributed Generation. Energy and Power Engineering, 9, 430-463. https://doi.org/10.4236/epe.2017.98029

[4] Chiradeja, P. and Ramakumar, R. (2004) An Approach to Quantify the Technical Benefits of Distributed Generation. IEEE Power \& Energy Society, 19, 764-773. https://doi.org/10.1109/TEC.2004.827704

[5] Lopes, J.A., et al. (2007) Integrating Distributed Generation into Electric Power Systems: A Review of Drivers, Challenges and Opportunities. Electric Power Systems Research, 77, 1189-1203. https://doi.org/10.1016/j.epsr.2006.08.016 
[6] Chowdhury, S. and Crossley, P. (2009) Microgrids and Active Distribution Networks. IET, London. https://doi.org/10.1049/PBRN006E

[7] Lasseter, R.H. (2002) Microgrids. Proceedings of the IEEE Power Engineering Society, New York, 1-2 January 2002, 305-308.

https://doi.org/10.1109/PESW.2002.985003

[8] Liang, T (2011) From Laboratory Microgrid to Real Markets-Challenges and Opportunities. Proceedings of IEEE International Conference on Power Electronics, Jeju, 30 May-3 June 2011, 264-271.

[9] Ustun, T.A., Ozansoy, C. and Zayegh, A. (2012) Modeling of a Centralized Microgrid Protection System and Distributed Energy Resources According to IEC 61850-7-420. IEEE Transactions on Power Systems, 27, 1560-1567. https://doi.org/10.1109/TPWRS.2012.2185072

[10] Jiang, W., et al. (2010) The Overview of Research on Microgrid Protection Development. Proceedings of International Conference on Intelligent System Design and Engineering Application, Beijing, 4-6 March 2010, 692-697.

[11] Kroposki, B., et al. (2008) Making Microgrids Work. IEEE Power and Energy Magazine, 6, 40-53. https://doi.org/10.1109/MPE.2008.918718

[12] Verma, R. and Siddiqui, M.A. (2015) Awareness on Microgrids and Various Protection Issues to Overcome in It. International Journal of Scientific \& Technology Research, 4, 27-29.

http://www.ijstr.org/final-print/may2015/Awareness-On-Microgrids-And-VariousProtection-Issues-To-Overcome-In-It.pdf

[13] Conti, S., Raffa, L. and Vagliasindi, U. (2009) Innovative Solutions for Protection Schemes in Autonomous MV Micro-Grids. International Conference on Clean Electrical Power, Capri, 9-11 June 2009, 647-654.

[14] Sortomme, E., Venkata, S.S. and Mitra, J. (2010) Microgrid Protection Using Communication Assisted Digital Relay. IEEE Transactions on Power Delivery, 25, 2789-2795. https://doi.org/10.1109/TPWRD.2009.2035810

[15] Parsai, A., et al. (2010) Protection of Meshed Microgrids withCommunication Overlay. Energy Conversion Congress and Exposition, Atlanta, 12-16 September 2010, 64-71.

[16] Dewadasa, M., et al. (2009) Control and Protection of a Microgridwith Converter Interfaced Micro Sources. International Conference on Power Systems, Karagpur, 27-29 December 2009, 1-6.

[17] Zamani, M., Sidhu, T. and Yazdani, A. (2011) A Protection Strategy and Microprocessor Based Relay for Low Voltage Microgrids. IEEE Transactions on Power Delivery, 26, 1873-1883. https://doi.org/10.1109/TPWRD.2011.2120628

[18] Pepermans, G., Driesen, J., Haeseldonckx, D., Belmans, R. and D’haeseleer, W. (2005) Distributed Generation: Definition, Benefits and Issues. Energy Policy, 33, 787-798. https://doi.org/10.1016/j.enpol.2003.10.004

[19] Coster, E.J. (2010) Distribution Grid Operation Including Distributed Generation. Eindhoven University of Technology, The Netherlands.

[20] Brown, A. and Ayres, F. (2012) Development of Distributed Generation in the United States. Report on the United States Experience on the Development of Distributed Generation Policies.

[21] Khan, S.A., Ali, R. and Hussain, S. (2009) Introduction to Microgrid. http://www.slideshare.net/Shahabkhan/microgrid-presentation 
[22] Salam, A., Mohamed, A. and Hannan, M.A. (2008) Technical Challenges on Microgrids. ARPN Journal of Engineering and Applied Sciences, 3, 64-69. https://www.arpnjournals.com/jeas/research_papers/rp_2008/jeas_1208_146.pdf

[23] Venkataramanan, G., and Illindala, M.S. (2007) Small Signal Dynamics of Inverter Interfaced Distributed Generation in a Chain Microgrid, IEEE Power Engineering Society General Meeting. Tampa, 24-28June 2007, 1-6.

[24] Pogaku, N., Prodanovic, M. and Green, T.C. (2007) Modeling, Analysis and Testing of Autonomous Operation of an Inverter-Based Microgrid. IEEE Transactions on Power Electronics, 22, 613-625. https://doi.org/10.1109/TPEL.2006.890003

[25] Lopes, J.A. (2005) Control Strategies for Microgrids Emergency Operation. International Conference on Future Power Systems, Amsterdam, 18 November 2005, 1-6. https://doi.org/10.1109/FPS.2005.204226

[26] Feng, W., Vilathgamuwa, M. and Choi, S.S. (2012) Mitigation of Harmonics of DFIGs in DC Microgrids. IEEE Energy Conversion Congress \& Exposition, Singapore, 15-20 September 2012, 1946-1953.

[27] Classification of Faults (2011).

https://www.elprocus.com/what-are-the-different-types-of-faults-in-electrical-powe r-systems/

[28] Blackburn, L. (2007) Protective Relaying Principles and Applications. CRC Press, Boca Raton.

[29] Hui, K. and Chao, M. (2011) Impact of Microgrid on Protection of Distribution Networks and Protection Strategy of Microgrid. Proceedings of International Conference on Advanced Power System Automation and Protection, Beijing, 16-20 October 2011, 356-359.

[30] Barker, P. and Mellow, D. (2000) Determining the Impact of Distributed Generation on Power Systems. IEEE Power Engineering Society, 3, 1645-1656.

[31] Kumar, P.A., Shankar, J. and Nagaraju, Y. (2013) Protection Issues in Microgrid. International Journal of Applied Control, Electrical and Electronics Engineering, 1, 1-12. http://airccse.com/ijaceee/papers/1113ijaceee02.pdf

[32] Al-Nasseri H., Redfern M.A. and Gorman, O. (2005) Protecting Micro-Grid Systems Containing Solid-State Converter Generation. Proceedings of the International Conference on Future Power Systems, Amsterdam, 18 November 2005, 1-5.

[33] Miveh, M.R., Gandomkar, M., Mirsaeidi, S. and Gharibdoost, M.R. (2012) A Review on Protection Challenges in Microgrids. Electric Power Distribution Conference, Tehran, 2-3 May 2012, 1-5.

[34] Soder, L (2009) Protection of Low Voltage DC Microgrids. IEEE Transactions on Power Delivery, 24, 1045-1053. https://doi.org/10.1109/TPWRD.2009.2016622

[35] Dugan, R.C. and McDermot, T.E. (2001) Operating Conflicts for Distributed Generation on Distribution Systems. Proceedings of Rural Electric Power Conference, Little Rock, 29 April-1 May 2001, A3/1-A3/6.

[36] Brearly, B.J. and Prabu, R.R. (2017) A Review on Issues and Approaches for Microgrid Protection, Renewable and Sustainable Energy Reviews, 67, 988-997. https://doi.org/10.1016/j.rser.2016.09.047

[37] Memon, A.A and Kauhaniemi, K. (2015) A Critical Review of AC Microgrid Protection Issues and Available Solutions. Electric Power Systems Research, 129, 23-31. https://doi.org/10.1016/j.epsr.2015.07.006

[38] Beddoes, A., Dickson, Y. and Kerford, L. (1999) Small-scale Single Phase Embedded Generators connected at LV. 15th International Conference on Electricity Distribution, London, 2-4 March 1999, 1-5. 
[39] Kin, B., et al. (2003) Agent Based Adaptive Protective Coordination in Power Distribution System. 17 th International Conference on Electricity Distribution. Barcelona, 12-15 May 2003, 1- 7.

[40] Sudhakar, P., Malaji, S. and Sarvesh, B. (2014) Protection and Control Challenges of a Distributed Generation Injected Distribution Network. International Journal of Advanced Research in Electrical, Electronics and Instrumentation Engineering, 3, $1-12$.

https://www.rroij.com/open-access/protection-and-control-challenges-of-adistribut ed-generation-injected-distributionnetworks.pdf

[41] Coster, E., Myrzik, J. and Kling, W. (2010) Effect of DG on Distribution Grid Protection. InTech, Rijeka.

[42] Hussain, B, Sharkh, S., Hussain, S., and Abusara, M. (2010) Integration of Distributed Generation into the Grid: Protection Challenges and Solutions. 10 th IET International Conference on Developments in Power System Protection, Manchester, 29 March 2010, 1-5.

[43] Laverty, D.M, Best, R.J. and John, M.D. (2015) Loss of Mains Protection System by Application of Phasor Measurement Unit Technology with Experimentally Assessed Threshold Settings. IET Generation, Transmission \& Distribution, 9,146-153. https://doi.org/10.1049/iet-gtd.2014.0106

[44] Mozina, C.J. (2001) Interconnection Protection of IPP Generators at Commercial/Industrial Facilities. IEEE Transactions on Industry Applications, 37, 681-688. https://doi.org/10.1109/28.924745

[45] Mozina, C.J. (2003) Interconnect Protection of Dispersed Generators. Technical Report, Beckwith Electric Co. Inc, Largo.

[46] Redfern, M.A., Brown, D. and Bartlett, M.G. (2001) Detecting Loss of Earth for Embedded Generation, IEEE 7 th International Conference on Developments in Power System Protection, Amsterdam, 9-12 April 2001, 90-93.

[47] Nikkhajoei, H. and Lasseter, R. (2007) Microgrid Protection. Proceedings of IEEE Power Engineering Society General Meeting, Tampa, 24-28 June 2007, 1-6. https://doi.org/10.1109/PES.2007.385805

[48] Mirsaeidi, S., et al. (2014) Progress and Problems in Microgrid Protection Schemes, Renewable \& Sustainable Energy Reviews, 37, 834-839. https://doi.org/10.1016/j.rser.2014.05.044

[49] Salman, S.K., King, D.J. and Weller, G. (2001) New Loss of Mains Detection Algorithm for Embedded Generation Using Rate of Change of Voltage and Changes in Power Factors. IEEE 7th International Conference on Developments in Power System Protection, Amsterdam, 9-12 April 2011, 82-85.

[50] Beheshtaein, S., et al. (2015) Protection of AC and DC Microgrids: Challenges, Solutions, and Future Trends. IEEE 41 st Annual Conference on Industrial Electronics Society, Yokohama, 9-12 November 2015, 5253-5260.

[51] Buigues, G., et al. (2013) Microgrid Protection: Technical Challenges and Existing Techniques. International Conference on Renewable Energies and Power Quality. Bilbao, 20-22 March 2013, 222-227. https://doi.org/10.24084/repqj11.262

[52] Funabashi, T. (2016) Integration of Distributed Energy Resources in Power Systems. Elsevier, Cambridge.

[53] Brearly, B.J. and Prabu, R.R (2017) A Review on Issues and Approaches for Microgrid Protection. Renewable and Sustainable Energy Reviews, 67, 988-997. https://doi.org/10.1016/j.rser.2016.09.047 
[54] Jenkins, N. (2000) Embedded Generation. IET, Hertfordshire. https://doi.org/10.1049/PBPO031E

[55] Hodgkingson, G. (1998) System Implications of Embedded Generation and Its Protection and Control. IEE Technical Report, Birmingham, 25 February 1998, 1-15.

[56] IEEE Recommended Practice for Utility Interface of Photovoltaic (PV) Systems (2000) IEEE Std 929-2000. http://ieeexplore.ieee.org/document/836389/

[57] IEEE Application Guide for IEEE Std 1547 (2009) IEEE Standard for Interconnecting Distributed Resources with Electric Power Systems. http://ieeexplore.ieee.org/servlet/opac?punumber $=4816076$

[58] Dugan, R.C., Key, T.S. and Ball, G.J. (2005) On Standards for Interconnecting Distributed Resources. Rural Electric Power Conference. San Antonio, 8-10 May 2005, D2/1-D2/8.

[59] Gururajapathy, S.S., Mokhlis, H. and Illias, H.A. (2017) Fault Location and Detection Techniques in Power Distribution System with Distributed Generation: A Review. Renewable and Sustainable Energy Reviews, 74, 949-958.

https://doi.org/10.1016/j.rser.2017.03.021

[60] Purushothama, G.K., et al. (2001) ANN Applications in Fault Locators. International Journal of Electrical Power \& Energy Systems, 23, 491-506. https://doi.org/10.1016/S0142-0615(00)00068-5

[61] Khorashadi, H. (2004) A Novel Approach to Detection High Impedance Faults using Artificial Neural Network. Proceedings of the Universities Power Engineering Conference, Bristol, 6-8 September 2004, 373-376.

[62] Hagh M.T., et al. (2007) Fault Classification and Location of Power Transmission Lines using Artificial Neural Network. Proceedings of the Power Engineering Conference, Singapore, 3-6 December 2007, 1109-1114.

[63] Cardoso, J., et al. (2004) Application of Neural-Network Modules to Electric Power System Fault Section Estimation. IEEE Transactions on Power Delivery, 19, 1034-1041. https://doi.org/10.1109/TPWRD.2004.829911

[64] Pradhan, A.K., et al. (2004) Higher Order Statistics-Fuzzy Integrated Scheme for Fault Classification of a Series-Compensated Transmission Line. IEEE Transactions on Power Delivery, 19, 891-893. https://doi.org/10.1109/TPWRD.2003.820413

[65] Das, B. and Reddy, J.V. (2005) Fuzzy-Logic-Based Fault Classification Scheme for Digital Distance Protection. IEEE Transactions on Power Delivery, 20, 609-616. https://doi.org/10.1109/TPWRD.2004.834294

[66] Das, B. (2006) Fuzzy Logic-Based Fault-Type Identification in Unbalanced Radial Power Distribution System. IEEE Transactions on Power Delivery, 21, 278-285. https://doi.org/10.1109/TPWRD.2005.852273

[67] Yadav, A.S. (2015) Fuzzy Inference System Approach for Locating Series, Shunt, and Simultaneous Series-Shunt Faults in Double Circuit Transmission Lines. Computational Intelligence and Neuroscience 1, 5, 1-12.

[68] Shuma, N.S. and Dorendrajit, T. (2016) Fuzzy Logic Based On-line Fault Detection and Classification in Transmission Line. Springer-Plus, 5, 1-14.

[69] Bedekar, P.P., et al. (2011) Fault Section Estimation in Power System Using Hebb's Rule and Continuous Genetic Algorithm. International Journal of Electrical Power and Energy System, 33, 457-465. https://doi.org/10.1016/j.ijepes.2010.10.008

[70] Jin., Q. and Ju, R. (2012) Fault Location for Distribution Network based on Genetic Algorithm and Stage Treatment. Proceedings of the Spring Congress on Engineering and Technology, Xi'an, 27-30 May 2012, 1-4. https://doi.org/10.1109/SCET.2012.6342090 
[71] Li, Y. (2012) A Fault Location Method Based on Genetic Algorithm for High-Voltage Direct Current Transmission Line. International Transactions on Electrical Energy System, 22, 866-878. https://doi.org/10.1002/etep.1659

[72] Majid, S.K. and Jamil, D.K. (2015) Fault Classification of Three-Phase Transmission Network using Genetic Algorithm. International Journal of Engineering and Applied Sciences, 2, 84-88. https://www.ijeas.org/download_data/IJEAS0207041.pdf

[73] Mokhlis, H. and Li, H. (2007) Fault Location Estimation for Distribution System Using Simulated Voltage Sags Data. Proceedings of the Universities Power Engineering Conference, Brighton, 4-6 September 2007, 242-247. https://doi.org/10.1109/UPEC.2007.4468953

[74] Mokhlis, H, Bakar, A., Talib, D. and Mohamad, H. (2010) The Improvement of Voltage Sags Pattern Approach to Locate a Fault in Distribution Network. International Review of Electrical Engineering, 5, 1159-1164. http://repository.um.edu.my/8129/1/VOL_5_N_3.pdf

[75] Mokhlis, H. and Li, H. (2011) Non-Linear Representation of Voltage Sag Profiles for Fault Location in Distribution Networks. Electrical Power and Energy Systems, 33, 124-130. https://doi.org/10.1016/j.ijepes.2010.06.020

[76] Awalin L.J. and Mokhlis, H. (2012) Improved Fault Location on Distribution Network Based on Multiple Measurements of Voltage Sags Pattern. IEEE International Conference on Power and Energy, Kota Kinabalu, 2-5 December 2012, 767-772.

[77] Elkhatib, M., Ellis, A., Biswal, M., Brahma, S. and Ranade, S (2016) Protection of Renewable-dominated Microgrids: Challenges and Potential Solutions. Technical Report (Sandia National Laboratories), Albuquerque, November 2016, 1-85.

[78] Hatziargyriou, N. (2014) Microgrids: Architecture and Control. Wiley \& Sons, Athens.

Submit or recommend next manuscript to SCIRP and we will provide best service for you:

Accepting pre-submission inquiries through Email, Facebook, LinkedIn, Twitter, etc. A wide selection of journals (inclusive of 9 subjects, more than 200 journals)

Providing 24-hour high-quality service

User-friendly online submission system

Fair and swift peer-review system

Efficient typesetting and proofreading procedure

Display of the result of downloads and visits, as well as the number of cited articles

Maximum dissemination of your research work

Submit your manuscript at: http://papersubmission.scirp.org/

Or contact epe@scirp.org 